\title{
Qué se entiende por gentilicio. Aproximaciones onomasiológicas, sintácticas y morfológicas. Prolegómenos ${ }^{1}$
}

\author{
Raïssa Kordic Riquelme* \\ Soledad Chávez Fajardo* \\ Universidad de Chile
}

\begin{abstract}
Resumen
En este artículo nos proponemos establecer los prolegómenos acerca de lo que se entiende por gentilicio. Por tratarse de una categoría designativa, es preciso dar cuenta de este concepto desde una óptica arquitectural. Por lo mismo intentaremos definir al gentilicio desde una perspectiva onomasiológica, sintáctica y morfológica. Este último nivel, el morfológico, uno de los más fructíferos al momento de estudiar el gentilicio, sobre todo por las amplias posibilidades que confluyen en la construcción de uno, es al que le destinaremos más atención. De allí que nos centraremos en los sufijos que operan
\end{abstract}

1 Financiado por el Programa de Apoyo a la Productividad Académica, PROA VID 2015 Universidad de Chile" (Academic Productivity Support Program, PROA VID 2015; University of Chile). Las autoras agradecen la lectura, revisión crítica y comentarios de este ensayo a Ricardo Dorado Puntch (Universidad Complutense de Madrid) y a Jairo Javier García Sánchez (Universidad de Alcalá): sin sus lecturas rigurosas y consejos metodológicos y teóricos, este ensayo, de seguro, no se sostendría.

* Para correspondencia, dirigirse a: Raïssa Kordic Riquelme (rkordic@uchile.cl) o a Soledad Chávez Fajardo (solchavez@gmail.com), Universidad de Chile, Facultad de Filosofía y Humanidades, Departamento de Lingüística; Av. Capitán Ignacio Carrera Pinto 1025, piso 3 , Ñuñoa, Santiago, RM, Chile. 
en este proceso derivacional y presentaremos una tabla que muestre los sufijos en lengua española más productivos, relativamente productivos y escasamente productivos, entre otros aspectos.

Palabras clave: gentilicio, topónimo, derivación sufijal, morfología histórica.

\title{
What IS A DEMONYM. ONOMASIOLOGICAL, SYNTACTIC AND MORPhOlOGiCAl approaches. Prolegomena
}

\begin{abstract}
In this paper we intend to establish the preliminary concepts of what is understood by demonym. Given that a demonym is a designative category, this concept must be addressed from an architectural standpoint. Therefore, we will try to define the demonym from an onomasiological, a syntactic, and a morphological perspective. We will mostly approach the latter, the morphological level, since it is one of the most fructiferous levels when studying the demonym, especially for the broad possibilities converging in its construction. Consequently, we will focus on the suffixes that operate in this derivational process, and present a table showing, among other aspects, the most productive, relatively productive, and scarcely productive suffixes in Spanish.
\end{abstract}

Keywords: Gentilicium/Demonym, toponym, suffix derivation, historical morphology.

Recibido: 19/07/2016

Aceptado: 24/01/2017

\section{PREÁMBULO}

El concepto lingüístico de origen o procedencia territorial, sea de personas, sea de animales o sea de cosas, que llamamos hoy por hoy gentilicio, es una de las categorías conceptuales más complejas y problemáticas de las lenguas naturales (cfr. Ferreccio y Jocelin (1992: 9), García Gallarín (2003: 579), Morera (2015: 7), entre otros), puesto que no responde a una fórmula idiomática unitaria, sino que se formaliza bajo expresiones lingüísticas diversas, ora morfológicas (iquiqueño, williense), ora sintácticas (de Chile, de Puerto Williams), ora léxicas (roto, coño). Asimismo, cada una de estas 
expresiones presenta problemas semánticos y formales, tanto sincrónicos como diacrónicos. Por otro lado, la tarea de catalogar los gentilicios puede resultar una labor interminable si no se tiene un corpus actualizado, sobre todo, por la cantidad de sufijos que suelen entrar en juego en su formación, así como las variedades en sus formaciones y la proliferación de sus remoquetes. Es por ello que muchas veces se haga referencia a los conocimientos de historia de la lengua y, en general, a una erudición más amplia para poder estudiarlos y analizarlos, erudición que va desde manejos en deonomástica, fonología, morfología, hasta etnografía e historia, entre otros. Algunos autores, sobre todo de escuelas más nuevas (por ejemplo, la Escuela de la Laguna, que ha trabajado intensamente en el gentilicio en los últimos años, cfr. Morera 2012b), van más allá respecto a la complejidad de abordar y tipologizar el gentilicio y se han propuesto, además, reconocer una categoría semántico-lingüística unitaria que supere el origen geográfico o étnico; algo, destacan, que excede la función que sea (sustantiva o léxica o adjetiva, por ejemplo), pues del contexto se determina qué es, justamente, un gentilicio. Otros autores (Almela Pérez 2013) ven en el gentilicio más que una categoría lingüística, con todas sus variables, una categoría designativa $\mathrm{y}$, partiendo de esa premisa, no se puede más que dar cuenta de su uso desde un punto de vista enciclopédico, es decir, total: tanto aspectos lingüísticos como extralingüísticos deberán ser tomados en cuenta al momento de estudiarlo, algo que, en extensión, si se piensa detenidamente, debería darse con toda aquella parcela de la gramática que no es propiamente gramatical, es decir, el léxico y los nombres propios. En este ensayo queremos dar cuenta, de una manera introductoria, del concepto "gentilicio" desde una perspectiva onomasiológica, sintáctica y morfológica. Creemos que solo con estas nociones claras podríamos, a posteriori, profundizar en aspectos como la historiografía del gentilicio o su función dentro de los procesos estandarizadores.

\section{1. ¿QUÉ ENTENDEMOS POR GENTILICIO?}

Intentar definir una noción extralingüística de origen o procedencia territorial de personas, animales y cosas, como es el gentilicio, es un aspecto que debemos tomar en cuenta antes de cualquier tipo de trabajo descriptivo. No carecemos de propuestas acertadas, como la que hicieron Ferreccio y Jocelin 1992 (cfr. pp 10-11), quienes intentaron organizar una definición desde una triple óptica: una perspectiva onomasiológica, otra funcional y 
otra morfológica. Morera 2015, por su parte, estructura una definición desde una perspectiva sintáctica, otra derivada y una última léxica; es decir, desde la relación más directa a la más figurada. Para efectos prácticos, hemos optado por estructurar nuestra propuesta de definición con ese trabajo de Ferreccio y Jocelin 1992, enriqueciendo estas observaciones, a casi 25 años de su publicación, con lo que han venido trabajando Morera y otros autores.

\subsection{Perspectiva onomasiológica}

\subsubsection{Gentilicios étnicos y gentilicios postoponímicos}

Desde un punto de vista onomasiológico, Ferreccio y Jocelin 1992 dan cuenta de dos semas para poder definir el gentilicio desde una categoría onomasiológica: 'persona' y 'lugar'. Nosotros, en cambio, hemos optado por 'ente' y 'lugar', puesto que se hace más extensiva la inclusión y más objetiva a efectos prácticos. Esto no quita que, para la aplicabilidad del gentilicio étnico, se deba restringir el sema a 'persona', como hacen Ferreccio y Jocelin 1992, tal como veremos a continuación. A partir de la aplicación de estos dos semas, se generan dos subclases de gentilicios: los étnicos y los postoponímicos (en un intento previo, muy general, esto ya había sido referido por la GRAE 1917 y Lenz 1925, como se verá en Chávez Fajardo y Kordic Riquelme, en prensa b). Para iniciar la discriminación en ambas subclases, los autores se remitieron a la voz misma (gens, gentis), para dar cuenta de la primera subclase, los étnicos (también llamados gentilicios primitivos, cfr. Morera 2012b), es decir, un grupo humano caracterizado por un cuadro de rasgos comunes (pensemos en chono, chango o mapuche, por ejemplo) sin que el nombre, necesariamente, traiga asociada la adscripción a un determinado lugar, aunque en algunos casos la zona geográfica habitada pueda llegar a formarse a partir del nombre de sus habitantes ${ }^{2}$. Morera 2011a, por ejemplo, sostiene que la preeminencia de los gentilicios étnicos

2 A propósito de esto último, Morera 2011a afirma: "A Letonia, Berbería, Arabia y Maketía las hacen, respectivamente, los letones, los bereberes, los árabes y los maketos" (77). Otras veces, continúa Morera, pueden ser ya no nombres de personas, sino de ríos: "Además de combinarse con denominaciones gentilicias, aparece también combinado con nombres de ríos (como Niger, base del topónimo Nigeria, Indo, base del topónimo India, Jordán, base del topónimo Jordania), nombres de personas (como Colombo, base del topónimo Colombia; Morelos, base del topónimo Morelia, Bolivar, base del topónimo Bolivia, Monroe, base del topónimo Monrovia), adjetivos (como liber, base del topónimo Liberia; austral, base del topónimo Australia), etc. Aunque no haya en estos casos un gentilicio de base, el derivado 
es totalmente histórica y que fue en la antigüedad cuando estos abundaron, puesto que la pertenencia a un grupo derivaba, posteriormente, en el nombre del lugar: "Es lo que sucedió en el caso de los gentilicios ítalo, franco, hispano, bereber, alemán, catalán, etc., que dieron lugar a los topónimos Italia, Francia, Hispania (España), Berbería, Alemania (antes también Alemaña), Cataluña, respectivamente" (Morera 2011a: 79). Por otro lado, algunos de estos gentilicios étnicos se formaron como remoquetes (vid. Chávez Fajardo y Kordic Riquelme, en prensa b): por ejemplo, los francos, en lengua franca significaba 'libres', en este caso, del Imperio Romano; los bereberes son producto de la adaptación del árabe del helenismo 'bárbaros'; los turcos, türk en antiguo turco, significaba 'fuerte' o los chicharreros, de Santa cruz de Tenerife, se conocían así por comer 'chicharros', algo que posteriormente pasó a ser el gentilicio, incluso, de toda la isla de Tenerife.

En esta primera subclase predomina el sema 'persona' y, eventualmente, el de 'lugar' (por ejemplo, persa se refiere al grupo humano, sema 'persona', pero se asocia, además, al lugar donde vivieron estos y que lleva su nombre, Persia). ¿Forman parte de la categoría nombres propios los gentilicios étnicos? Si bien, señala Garcés Gómez (1988: 1685), se suele hacer esta afirmación, los usos de los gentilicios étnicos son semejantes a los de cualquier apelativo común, puesto que indican aspectos definitorios delimitados convencionalmente, es decir, persona originaria, procedente o perteneciente a un determinado grupo. Los nombres comunes, bien se sabe, son descriptivos, puesto que el referente en sí posee determinadas cualidades y atributos; en cambio, los nombres propios denominan el objeto identificándolo e individualizándolo de los demás de la misma clase sin implicar sus atributos. En rigor, los nombres propios son marcas de identificación sin contenido semántico, mientras que los nombres comunes son unidades significativas. Esto no quita que en determinados casos un gentilicio étnico designe, además, el punto geográfico donde ha nacido la persona, por lo que se entiende como nombre propio, un caso especial de nombre propio ${ }^{3}$ (cfr. Garcés Gómez 1988: 1686). Tanto Ferreccio y Jocelin 1992, como Morera 2011a insisten en el carácter de "verdadero gentilicio" que tienen los étnicos, sobre todo desde una óptica onomasiológica. Este

resultante presenta exactamente la misma estructura gramatical que la de los casos con tema gentilicio" (78-79).

3 Incluso, afirma la autora, se ha propuesto la constitución de una categoría intermedia de "comon proper names", por el hecho de que pueden emplearse tanto en singular como en plural, igual que los nombres comunes, sin perder por ello el estatus de nombre propio (cfr. Garcés Gómez 1988: 1685). 
último, por ejemplo, atrae las reflexiones de Benveniste 1974, respecto al sistema latino, en donde la civitas (ciudad) latina deriva de civis (ciudadano) y no al revés: "En el modelo latino, el término primario es el que califica al hombre en cierta relación mutua, civis. Ha engendrado el derivado abstracto civitas, nombre de colectividad" (Morera 2011a: 281); es decir, desde esta lógica, es el nombre del individuo el que se impone semánticamente y de allí deriva el nombre del lugar ${ }^{4}$.

Por otro lado, a partir de nombres de lugar se generan derivados, es decir, gentilicios derivativos (cfr. Ferreccio 2006: 178, Morera 2015: 16) o adjetivos gentilicios (GRAE 2009: §7.6 ${ }^{\mathrm{a}}$, Morera 2011a): Chile > chileno; Pica > piqueño; Copiapó > copiapino; La Habana > habanero; Europa $>$ europeo; Londres > londinense. Estos, que Ferreccio y Jocelin (1992: 10) llaman postoponímicos, constituyen el grueso de los gentilicios ${ }^{5}$. A diferencia de los étnicos, prevalecen en los postoponímicos el sema 'lugar' y, eventualmente, el de 'ente'. Es más, en su estructura semántica el nombre de lugar actúa como núcleo o materia básica de la combinación con un sufijo. Según Morera (2011b: 104), estos serían los que presentan "mayor fuerza gentilicia" pues son los que significan de forma mostrativa "lugares únicos". Respecto al sema 'lugar', puede provenir de dos tipos de nombres: nombres propios o nombres comunes de lugar. Los primeros, topónimos, para la mayoría de los autores son los que, en propiedad, son gentilicios, frente a los segundos, los nombres comunes, para muchos, no gentilicios en rigor, los cuales son semánticamente más simples, pues dan cuenta de una adscripción de una persona, animal o cosa a un tipo de lugar, pero no a un lugar concreto (ciudadano, costino, isleño, lugareño, nacional, serrano),

\subsubsection{Delimitaciones semánticas}

Las reflexiones relacionadas con algunos aspectos semánticos del gentilicio postoponímico no son pocas; por eso, nos proponemos, además, delimitar este aspecto. Para ello, constatamos, se comprometen tres instancias: en primer lugar, establecer la identidad de la entidad geográfica designada por el

\footnotetext{
4 Morera describe de esta manera la relevancia de un gentilicio étnico: "Lo que tiene aquí existencia independiente es el sujeto, el hombre, en tanto que la tierra se considera como una mera derivación o extensión de él. La relación entre pueblo y habitante se orienta aquí del individuo a la tierra, o del individuo a la colectividad" (Morera 2011a: 77).

5 Por ser derivados adjetivales, pertenecen al mismo orden de los calificativos derivados de algún geónimo, es decir: "nombres propios o generales de circunstancias naturales o facticias del paisaje, que se forman sustancialmente con los mismos sufijos: ribera-ribereño, Alpesalpino, playa-playero, costa-costino, costero, arena-arenero" (Ferreccio y Jocelin 1992: 10).
} 
topónimo-base; en segundo lugar, identificar la relación que se establece entre esa entidad geográfica y la entidad calificada; y, en tercer lugar, delimitar la identidad de la entidad calificada (cfr. Ferreccio y Jocelin 1992: 11). Esta dinámica, podemos apreciar, ya no radica en una semántica invariable, sino en una suma de contenidos sumamente circunstanciales, variantes y accidentales (caracteriza Morera 2015: 27).

En primer lugar, la identidad geográfica designada por el topónimo se basa, para algunos (cfr. Ferreccio y Jocelin 1992: 11), en topónimos propiamente demográficos, es decir, aquellos que denominan una entidad geográfica poblada. Estas entidades geográficas son de dos tipos: las estrictamente pobladas, llamadas, por lo general, localidades, que incluyen pueblos, aldeas, ciudades, villorrios (por ejemplo, Madrid, Penco, Linderos, Viña del Mar). También se consideran otras localidades, latamente pobladas y que suelen tener una identidad política y administrativa, incluso tradicional (España, Europa, Ñuñoa-como comuna-o Matucana-como barrio-). Este rango permite, por lo tanto, la inclusión de unas entidades en otras: Lavapiés dentro de Madrid; dentro de España; dentro de Europa, por lo que un ente (sea persona, sea animal, sea cosa) es susceptible de más de un gentilicio: ñuñoíno, santiaguino, chileno, latinoamericano.

En segundo lugar, la identificación de la relación entre la entidad geográfica y la entidad calificada suele ser difusa, puesto que el postoponímico puede hacer referencia a la persona, animal o cosa que está accidental o externamente relacionado con el lugar designado por la base del gentilicio, o bien, que está esencial o internamente relacionado con el lugar designado por la base del gentilicio (cfr. Morera 2015: 29-32). Si hablamos, por ejemplo, de [+humano], esta relación puede consistir en una mera estancia en el lugar determinado, en una residencia y también en el nacimiento, la personalidad civil, etc. De este modo, el mismo sujeto puede añadir otros calificativos: venezolano por su morada; argentino por su nacimiento; chileno por su nacionalidad oficial o italiano por su linaje. De allí, por ejemplo, la doble o triple nacionalidad.

En tercer lugar, la entidad calificada por el gentilicio puede apuntar a todo ente, tanto material como ideal (una pintura francesa; una historiografía chilena). Morera (2015: 29-32), por ejemplo, distingue semánticamente, en este caso, a la persona y no persona que pertenecen a un lugar; mientras que la persona está relacionada por una serie de fenómenos (históricos, culturales, climáticos, etc.), todo ente que no sea persona está determinado por el medio natural de dicho lugar. Asimismo, los postoponímicos desarrollan acepciones secundarias referidas al aspecto, el comportamiento, los hábitos gastronómicos, la vestimenta, la forma de hablar, las aspiraciones, la ideología, la historia, la economía, entre otros (seguimos en esto a Morera 
2015: 32), tanto de personas como de no personas (sean animales, plantas, fenómenos naturales, minerales, etc.).

\subsection{Perspectiva sintáctica: el sintagma de ORIGEN O PROCEDENCIA TERRITORIAL}

La primera y más básica realización sintáctica que expresa la relación, origen o procedencia territorial de personas, animales y cosas, se hace en español mediante la preposición de, seguida del nombre que actúa como régimen o complemento de la preposición, que es el lugar de que se trata; en términos más simples, un complemento del nombre (cfr. Valdivieso y Soto-Barba 2002, Morera 2015). Es decir, una construcción preposicional, que podemos llamar sintagma de origen o procedencia territorial (si seguimos a Morera 2015). Esta construcción se establece como la forma más precisa y primaria de significar la relación gentilicia, del momento que es un procedimiento gramatical que el hablante puede usar libremente, sin requerimientos normativos o del ejercicio de una disponibilidad léxica que exige, las más veces, el uso de gentilicios (cfr. Morera 2011b: 96). Asimismo, su misma virtud de neutralidad respecto a otras construcciones gentilicias lleva a que sea la fórmula más recurrente en las definiciones de gentilicios en los diccionarios. Morera (ver 2011b: 27, 97 y 2015: 13) distingue, desde el punto de vista de la naturaleza semántica del nombre, dos variantes:

1) de + nombre propio de lugar, que sería la construcción gentilicia per $s e$, puesto que no admite otra interpretación que no sea la gentilicia, sobre todo por la exclusividad que la da la cualidad de nombre propio. Se pueden encontrar zonas que solo manejan este tipo de gentilicios y las razones son variadas: para algunos (cfr. Garcés Gómez 1988), esto se produce cuando los nombres de las localidades son compuestos, cuando tienen un elevado número de sílabas, o en aquellos casos en los que la adición del sufijo podría hacer difícil la correcta pronunciación de la palabra, por ejemplo, con las fórmulas de, los de, gente de, entre otros: de Bellavista, los de Cacique, los de Puro Chile, los de la Panamericana; colono de Bahía Erasmo, colono Bernardo O'Higgins, gente de Toledo, la gente de Los Chulluncanes; colono de Monte Águila; de la Costa del Báker. Para otros autores (cfr. Morera 2015), el uso sintagmático se da en aquellas zonas de establecimiento más tardío, como por ejemplo, en Canarias. Es más, Las Palmas de Gran Canaria, capital de la isla de Gran Canaria y de toda la provincia oriental del archipiélago, posee el gentilicio de las Palmas (aunque puede encontrarse palmense/a, este es minoritario). Kordic y Ferreccio (2014: III) destacan este 
tipo de construcción y su proliferación en la aplicación de la encuesta, lo que confirma que es una tendencia usual, mas deberá analizarse posteriormente cuáles son las razones para esta realidad en Chile. Dentro de este grupo, Morera (2015) distingue, además, la naturaleza referencial del nombre en dos variantes distribucionales, primero, donde el nombre propio de lugar designa a una persona más o menos determinada, en tanto es singularizadora: sindicalistas de Iquique, los de Potrerillos; segundo, donde el nombre propio designa animales y cosas, por lo que se puede hablar de construcciones gentilicias: mangos de Pica, atún de isla de Pascua.

2) de + nombre común de lugar, posee una función gentilicia más atenuada, al ser un nombre común, la significación es descriptiva, cual ejemplar de una clase nocional, por lo que no se refiere a un lugar determinado. Más que una expresión gentilicia, entonces, sería una expresión calificativa del tipo de la sierra, del campo, de la costa.

Sin embargo, este uso sintagmático no está exento de algunos cuestionamientos, como el de su naturaleza gentilicia misma, cosa que se comprueba al examinar la bibliografía existente y verificar que esta construcción no suele incluirse dentro de los repertorios gentilicios. Por ejemplo, Morera (2015: 12) argumenta la "incapacidad [de este tipo de realización sintáctica] para archivar la información denotativa que expresa en cada caso, por su propio carácter sintáctico, de unidad circunstancialmente construida"; dicho en otras palabras, frente a las construcciones morfológicas (étnicas $\mathrm{y}$, sobre todo, postoponímicas), las cuales poseen una fuerte carga interna, puesto que el componente semántico es la base de la voz en cuestión, en estas construcciones analíticas la relación es externa, ya que el topónimo se presenta como un punto de referencia independiente, por lo que tiene mucho menos fuerza caracterizadora. Por otro lado, es esta una realización elemental, puesto que cualquier relación de origen o procedencia territorial puede expresarse mediante esta construcción preposicional.

\subsection{FUNCIÓN DEL GENTILICIO}

Como ya hemos visto en 2.1, la división de los gentilicios en étnicos o postoponímicos ha favorecido, muchas veces, el cruce funcional en un solo orden, puesto que voces que son primordialmente sustantivos (los étnicos) se mezclan con voces que son derivados adjetivales (los postoponímicos). Por lo mismo es necesario, aunque sea de una manera panorámica, esclarecer cuáles son las funciones de ambos tipos de gentilicios, sobre todo de los 
postoponímicos, tanto por su función adjetiva, como por la posibilidad que tienen estos de sustantivarse (cfr. Bosque 1999 y GRAE 2009 §7.6 a). Los postoponímicos, no hay que olvidar, son adjetivos de relación, por lo que forman parte de la categoría derivacional más importante numéricamente hablando de la lengua española, con más de 70 sufijos (cfr. Rainer 1999: 4611), algo que se verá de forma más detallada en el apartado 1.3. Este tipo de categoría derivacional posee un común denominador semántico que puede expresarse como "que tiene que ver con $\mathrm{N}^{\text {" }}$. Esta fórmula se aplica en la estructura de definición lexicográfica de un gentilicio en el diccionario "Perteneciente o relativo a", que es la significación básica de los adjetivos de relación, por lo que es, en rigor, una significación mostrativa o identificadora. Por ello en las formas puertomontino, chillanejo, colombiano, chilote, ariqueño, paulista y guyanés se da la idea de atribución de Puerto Montt, Chillán, Colombia, Chiloé, Arica, Sao Paulo y Guyana, respectivamente, al sustantivo que los rige, porque en ellos los nombres de lugar aluden a un territorio determinado, con una geografía, una historia y una cultura propias. Frente a los topónimos referidos, de clara significación espacial, sus derivados pasan a significarse de forma adjetiva como rasgo semántico de algo que ocupa un lugar en la naturaleza, que, en el caso de los gentilicios, es el nombre de persona, animal o cosa que lo rige (cfr. Morera 2015: 26-27).

Por otro lado, la posibilidad que tienen los postoponímicos de sustantivarse nos acerca a las distinciones que se han hecho entre nombre y adjetivo. Para ello atraemos las consideraciones de Wierzbicka (1986) y de Bosque (1999), respecto a la vinculación semántica entre el concepto de clase y de prominencia del grupo de individuos que esa clase establece. Es decir, todos los sustantivos designan clases de entidades, pero los adjetivos que pasan a ser sustantivos con mayor facilidad son aquellos que designan propiedades de los individuos lo suficientemente relevantes como para caracterizar grupos humanos reconocibles más fácilmente. Es decir, este factor no se basa en agrupar a los miembros porque posean algo en común, sino en la valoración o la relevancia de la clase así obtenida; es decir, clases que tienen relevancia social, puesto que tienen identificación categorial. Es, entonces, el factor diferenciador, es decir, el pertenecer a grupos reconocibles por alguna propiedad diferenciadora, lo que la comunidad percibe como relevante. De allí que los adjetivos que designan características geográficas, entre otras, constituyen un campo propicio para convertirlas en clases y,

6 Son raros los adjetivos relacionales derivados de topónimos que no se suelen usar como gentilicios, como habano (frente a habanero), destaca la última edición de la GRAE (§ 7.6 c). 
por tanto, para designar sustantivos y es por esto por lo que los gentilicios postoponímicos entran en este grupo.

\subsection{Perspectiva morfológica}

Sin lugar a dudas, esta perspectiva es la que más reflexiones, investigaciones $\mathrm{y}$ trabajos ha generado, sobre todo por la riqueza derivacional que se da en los gentilicios. Pensamos, sobre todo, en los gentilicios postoponímicos como objeto de investigación, puesto que son adjetivos derivados de un topónimo. No hay que olvidar que el procedimiento canónico de la derivación nominal consiste en aislar la raíz o tema derivativo del nombre, sustrayéndole morfemas desinenciales o sufijales para anexar, posteriormente, a la raíz morfológica lexemática, el morfema correspondiente. En el caso de los gentilicios postoponímicos, cuya raíz es onomástica, no habría marcas desinenciales, puesto que estas quedan neutralizadas, al ser el topónimo un designativo en sí mismo; por lo tanto, si un topónimo posee aparentes desinencias categoriales, algunas reconocibles por los hablantes, estas serán solo semidesinencias (o seudodesinencias, cfr. Chávez Fajardo y Kordic Riquelme a, en prensa), según las lecturas onomásticas.

De los étnicos, en cambio, al ser nombres primitivos, se generan los derivados, que son los topónimos (persa $>$ Persia). Sin embargo, esto no exime que los gentilicios étnicos tengan, a su vez, formantes ${ }^{7}$, con una estructura morfológica más simple que la que veremos en los postoponímicos (cfr. GRAE, 7.6 s, Morera 2012c: 127), lo que hace que su proceso de derivación forme parte, casi, de una serie cerrada (cfr. Ferreccio y Jocelin 1992: 19). Tal es el caso del sufijo -ia. Este sufijo tiene distinta prosodia según su foco de difusión: átono -ia por el latín; tónico -ía, por el griego $(\text { galo }>\text { Galia; turco }>\text { Turquía })^{8}$. Además, se encuentran otros formantes para

Llamados postétnicos, para Ferreccio y Jocelin 1992: 18.

8 Ferreccio y Jocelin (1992: 18) ejemplifican, con el caso de Rumania, en donde se muestra la confluencia de ambas tendencias: Rumania en Latinoamérica y Rumanía, en parte, en la península ibérica (hoy se está recuperando el empleo de Rumania, con la prosodia latina, cfr. García Sánchez 2009: 106-109). Sin embargo este ejemplo, señalan los autores, es complejo, puesto que rumano no sería, en el sentido estricto, un étnico, puesto que es el romano de Roma, pero se comporta como étnico, señalan los autores, al generar un nuevo topónimo: Roma > rumano > Rumania. Otro ejemplo interesante es el que entrega Morera (2011a: 77), el cual es Maketía (nosotros registramos Maketanía), para referirse a la patria de los no vascos, cuya base es la voz maketo que empezó a usar Sabino Arana para designar despectivamente al "inmigrante de otra región española al País Vasco". Maketía o Maketanía 
los étnicos, como el germánico de origen celta -landia (finno > Finlandia; curlo $>$ Curlandia y sigue, además, generando nuevos nombres, como swazi $>$ Suazilandia, thai > Tailandia) o el persa -stán (kazajo > Kazajistán; turco $>$ Turquestán; afgano > Afganistán; kurdo > Kurdistán). Lo mismo sucederá con los remoquetes (cfr. Chávez Fajardo y Kordic Riquelme $b$, en prensa): cuando, en algunos casos, se instalan como gentilicios no marcados, su topónimo también se forma con el gentilicio -i/ía (Francia o Berbería, por ejemplo).

Dentro del aspecto estrictamente morfológico, a partir del corpus de gentilicios existentes, se ha revelado un rasgo común en algunas situaciones de formación: la irradiación (cfr. Ferreccio 2006: 185), en donde se da la difusión de alguna propiedad lingüística de diversa naturaleza. Por ello se la ha categorizado en irradiación onomástica e irradiación analógica o temática (ambas tratadas en detalle en Chávez Fajardo y Kordic Riquelme a, en prensa).

\subsubsection{Inflexión categorial}

Desde un punto de vista de inflexión categorial, se presentan algunas situaciones anómalas, como la invariabilidad de número de algunos étnicos: dialectos yunga, indios hopi, reducciones piapoco; o de género: belga, árabe, mapuche, balear. Asimismo, en los postoponímicos, por su misma condición onomástica, en donde las posibles desinencias quedan neutralizadas, se tiende, a efectos morfosintácticos, a tratar con las categorías nominales no marcadas: masculino, singular, como en "Mi Buenos Aires querido"; "Las Miras es bonito, pero queda lejos".

\subsubsection{Los sufijos}

Sin embargo, es la riqueza sufijal y las posibilidades de derivación en lengua española lo que hace de la distinción morfológica el apartado más fructífero dentro de los estudios de los gentilicios postoponímicos. Justamente, porque estos se establecen como una serie abierta, ya que de cualquier topónimo se puede generar un gentilicio correspondiente ("como una virtualidad puesta inmediatamente en manos de los usuarios, mediante una simple regla de generación -que permite derivaciones también imprevisibles- y un repertorio de sufijos" describen Ferreccio y Jocelin 1992: 19). Esto hace

es, por tanto, la derivación de maketo. Un caso particular es el que presenta Morera 2012c, con Bélgica, derivado de belga, donde el formante es -ico/a. 
que, del repertorio de sufijos existentes, se puedan construir gentilicios virtuales perfectamente canónicos; por ejemplo, tenemos, en el clásico caso de la homonimia con el topónimo Santiago, la recurrencia a diferentes sufijos, lo que genera la proliferación de gentilicios, a saber: santiagués, santiagueño, santiaguero, santiaguino, santiaguense. $\mathrm{O}$, por el contrario, de una homonimia con el topónimo, se construye el mismo gentilicio, como en cordobés para Argentina, Colombia, España y México o leonés para España, México y Nicaragua. Asimismo, por medio de la morfología, se pueden obtener otros gentilicios, a veces usados en diversos contextos o en diferentes épocas, por ejemplo: Madrid > madrileño, matritense; Costa Rica $>$ costarricense, costarriqueño; Huelva $>$ onubense (derivación esperable de Onuba); Calatayud > bilbitano (por la prerromana Bílbilis); Concepción $>$ penquista (por eventualidades históricas); Valparaíso > porteño (por la ubicación de la ciudad). Asimismo, observan algunos autores (cfr. Pena 1999: 4361), la disposición y riqueza de estos hace que muchas veces encontremos sufijos sinónimos o equifuncionales, en distribución potencialmente libre o impredecible, que en el caso de los gentilicios postoponímicos, pueden agruparse en conjuntos de alomorfos: de un lado - ense y -és y, de otro, -ano, -iano, -eno, -ino, por ejemplo. Por lo tanto, y tal como observa la última edición de la GRAE ( $\$ 7.6 \mathrm{c}$ ), no es posible prever el sufijo que forme adjetivos gentilicios con cada nombre de lugar.

Sin embargo, hay que hacer la salvedad de que los sufijos que integran los gentilicios no son, en sentido estricto, sufijos gentilicios (vid. §1.3.2.2). En rigor, lo que significan estos sufijos que se prestan para derivaciones gentilicias es una "cuantificación interna de la sustancia del nombre que actúa de base", o sea, del topónimo, si seguimos a Morera (2011b: 104). Lo interesante es que estos sufijos no significan en sí mismos la relación espacial de una manera igual, sino que cada uno de ellos la expresa, desde una óptica semántico-lingüística, de una manera particular, puesto que no presentan, cada uno, el mismo valor idiomático. Sin embargo, a su vez, todos, cual paradigma, significan lo mismo desde un punto de vista referencial: el ser sufijos gentilicios.

Esto conlleva una serie de implicaciones en relación con la morfología del gentilicio: primero, que se puede hablar de sufijos gentilicios siempre y cuando integren uno, aunque en lo semántico no sean, exclusivamente, sufijos gentilicios. Con ello citamos a Morera, para quien no hay sufijos de significación gentilicia, sino sentido gentilicio de determinados sufijos (2015: 21). Algunos autores (cfr. Ferreccio y Jocelin 1992: 21), en relación con la proliferación de sufijos no estrictamente gentilicios, en cuyo ejercicio se forman derivados de todo tipo, sobre todo en geónimos en su más laxo sentido (es decir, no necesariamente demográficos: pampino, costino, 
serrano), propusieron restringir el término de gentilicio a nombres que provienen de topónimos estrictamente demográficos, es decir, aquellos que denotan "entidad demográficamente estructurada", es decir, una "localidad constituida por un conjunto de viviendas agrupadas, que actualmente tiene, o tuvo anteriormente, una población estable de al menos cincuenta habitantes, y que muestra cierto grado de autonomía y diferenciación respecto de todo otro lugar poblado inmediato" (Ferreccio y Jocelin 1992: 44). Esto hace que geónimos cuyo rango demográfico es impreciso, como comunas, comarcas, barrios, áreas o circunstancias geográficas queden fuera de esta inclusión. Sin embargo el ejercicio práctico de las encuestas dialectales, por ejemplo, y la riqueza de gentilicios hace, al mismo tiempo, que esta postura se descarte (cfr. Kordic y Ferreccio 2014: 10), sobre todo para dar cuenta de la riqueza en este campo.

Por otro lado, desde una perspectiva morfológica, el gentilicio no se da por el ejercicio de determinados sufijos, sino por el hecho de presentarse una raíz toponímica que el oyente o lector pueda identificar. Ferreccio y Jocelin 1992 lo ejemplifican con chillanejo, puesto que si un hablante no reconoce el topónimo (Chillán) pensará, posiblemente, que forma parte de la familia léxica de chillar. Justamente este último ejemplo pone en tela de juicio una de las problemáticas dentro de la morfología descriptiva: qué se entiende por sufijo y qué rol posee este cuando forma parte de un gentilicio, puesto que, entre otros aspectos, a menudo no es posible aislar la fisonomía exacta del sufijo en cuestión. Al respecto, Almela Pérez 2013 hace un minucioso rastreo bibliográfico de lo que se ha entendido como sufijo y cómo se lo puede tipologizar ${ }^{9}$, centrándose, sobre todo, en los que funcionan

\footnotetext{
9 Para ello, Almela Pérez continúa con Alarcos Llorach (1974: 78) quien distingue entre derivativos heterogéneos y derivativos homogéneos, dependiendo de si se produce una modificación en la categoría del derivante. Por otro lado, Seco (1989: 208) distingue entre sufijos significativos y sufijos apreciativos. Los sufijos significativos modifican el significado de la raíz, derivando una palabra en otra distinta, incluso de distinta clase; con los sufijos apreciativos la palabra sigue siendo la misma, y el empleo de ellos obedece a la voluntad del hablante. Sin embargo, los tratamientos que más destaca Almela Pérez 2013 son, en primer lugar, el de Faitelson-Weiser (1981), quien clasifica los sufijos en tres grupos, primero, los lexicalizadores, en donde el derivado es un subgénero del primitivo, pero es de la misma clase semántica y gramatical, por ello la sufijación es endocéntrica; segundo, en lexicalizadoresprecategorizadores, en donde la lexicalización que se produce es exocéntrica, puesto que la sufijación altera la clase semántica o gramatical del derivante. Esta puede ser homogénea, en donde se produce el cambio de la clase semántica (libro > librero) o heterogénea, en donde se produce el cambio de la clase gramatical y, tercero, en no lexicalizadores, en donde la sufijación no produce lexicalización alguna, sino solo una cuantificación o una modificación de actitud (librito, libraco). En segundo lugar, destaca el de Varela (1990), quien propone establecer una escala de incidencia sintáctica en la sufijación, por lo que habría cuatro tipos
} 
como gentilicios, puesto que la dicotomía clásica que se ha establecido para clasificarlo, es decir, entre apreciativos (diminutivos, aumentativos y despectivos) y no apreciativos (todo el resto), no resulta suficiente para esta tipologización en particular. En cambio, el autor propone dos aspectos para su tipologización: si en su ejercicio hay cambio de categoría o si en su ejercicio hay alteración lexémica (o cambio de sema o cambio de semema). A partir de esta distinción, el autor propone tres tipos de sufijos: endocéntricos, en donde se alteran solo los semas del derivante (ventana $>$ ventanica, perro $>$ perrazo, niño > niñato); exocéntricos homogéneos, en donde se altera el semema del derivante, pero no su categoría gramatical (cocina $>$ cocinero) y exocéntricos heterogéneos, en donde se altera el semema y la categoría gramatical del derivante (campo > campestre). En el caso de los sufijos gentilicios serían exocéntricos homogéneos o heterogéneos, puesto que generan tanto sustantivos como adjetivos. Lo relevante de esta distinción (lo veremos en la tabla de §1.3.2.2) es que el valor del sufijo en sí mismo, sea endocéntrico o exocéntrico en general, dependerá de la realización sintáctica en el gentilicio, así como su adjetivación o su sustantivación.

\subsubsection{Prosodia de los sufijos}

Respecto a la prosodia de los sufijos, estos son mayoritariamente tónicos y generalmente disílabos paroxítonos, por lo que se desplaza el acento desde el tema toponímico al sufijo mismo (Temúco > temucano; Bérgamo $>$ bergamasco; Píca > piqueño; Israel > israelíta). Tónico es, también, el sufijo monosílabo -és, en donde también hay un desplazamiento acentual (Aragóon > aragonés; Irlánda > irlandés; Japón $>$ japonés). Átonos serían el disílabo -ico (eólico, hispánico, jónico, aquitánico, pérsico), claramente derivado de un étnico, -igo presente solo en arábigo y el monosílabo -o (navarro, paraguayo, chino, suizo).

\subsubsection{Identificación de los sufijos}

En lengua española los sufijos gentilicios de más larga data, derivados del latín, serían -ense, -ano, -és, -ino y -eño, mientras que otros se han incorporado con esta función recientemente, como - ero (cfr. Morera 2011a: 76). Algunos de ellos, si bien tuvieron gran productividad antaño, parecen no

de sufijos: 1. Se cambia la categoría léxica del derivante y la estructura argumental (moderno $>$ modernizar); 2 . Se cambia la categoría léxica del derivante pero no la estructura argumental (interrumpir $>$ interrupción); 3. No se cambia la categoría léxica del derivante, pero afectan algunos rasgos léxicos fundamentales (fruta $>$ frutero); 4 . No se cambia la categoría léxica del derivante ni se afectan algunos rasgos léxicos fundamentales (casa $>$ casita). 
tenerla en la actualidad. Al respecto, Rainer (1999 §70.3.1.3) lo ejemplifica con el sufijo '-ico/a (hispánico, jónico). En otros casos, existen sufijos de escasa productividad, pero reutilizados recientemente, como -ano/a (keniano, que alterna con keniata). Respecto a la frecuencia de los sufijos, los que poseerían mayor productividad en lengua española serían -ano/a, -ense, -eño/a, -és/a, -í, -iano/a, de entre un total de más de cincuenta posibilidades (cfr. Rainer 1999 §70.3.1.3). De allí que el mismo Rainer hable de sufijos productivos y de sufijos no productivos.

La aparición de uno u otro de estos sufijos está determinada por razones históricas, fonéticas o semánticas, entre otras (aspecto que detallamos en Chávez Fajardo y Kordic Riquelme a, en prensa). Esto hace que no todos presenten la misma frecuencia de uso ni la misma distribución geográfica. Justamente, en este último aspecto, con los estudios y encuestas de tipo dialectal a los que hemos accedido (ver, sobre todo, para la península ibérica, Garcés Gómez 1988 y para Chile, Kordic y Ferreccio 2014), se podría constituir un verdadero mapa de isoglosas a partir, precisamente, de la presencia de sufijos gentilicios en determinadas zonas. Por otro lado, los sufijos, por preferencias de empleo y manejo de uso, se seleccionarán, muchas veces, por precedentes dentro del medio, por lo que se puede hablar de irradiación analógica, es decir, de los gentilicios que se usen y conozcan en determinada zona, se derivarán otros con estructura similar (cfr. Chávez Fajardo y Kordic Riquelme a, en prensa).

En el caso de Chile, respecto a las preferencias sufijales y su distribución, ya Oroz (1934) afirmaba que no había más de ocho sufijos gentilicios, todos repartidos geográficamente. Posteriormente, Valdivieso y Soto-Barba (2002) propusieron que -ino/a, - ano/a, -eño/a y -ense son los más frecuentes, con una serie de lineamientos que van desde lo estrictamente lingüístico hasta lo más contextual e histórico. Ferreccio (2006), por su parte, presenta, después de discernir entre gentilicios aparentes (por ser "oficinescos") y los de uso, la siguiente frecuencia: -ino/a, 56\%; -ano/a, 24\%; -ense, 12\%; -eño/a, $4 \%$ y -és, $4 \%$.

A continuación presentamos un cuadro con los sufijos que han operado en la formación de gentilicios en lengua española. El rastreo, como se verá, ha sido bibliográfico. Hay casos, como en -áceo/a (cfr. Rainer 1999), -ate (cfr. Ferreccio y Jocelin 1992) o -eaco (cfr. Ferreccio y Jocelin 1992) que hemos decidido excluir de la tabla, sobre todo por la nula relevancia gentilicia que poseen, según nuestro peritaje. Asimismo, los sufijos gentilicios más prolíficos son precedidos de un asterisco. En algunos casos, incluiremos los gentilicios con que contienden las formas expuestas, como una forma de explicitar que no es la forma única. Asimismo, no buscamos, al momento de nombrar casos, exponer su totalidad, solo dar cuenta de una muestra. 
Merecería un estudio posterior el análisis y cotejo de aquellos, creemos, sufijos gentilicios hápax que hemos detectado, puesto que solo hemos encontrado un único caso en donde estos operan (pamplonica, bonicho, parisién, arábigo, santibañijo, llanisco, rinconisto, guardiolo, miñoto, portugalujo, capilurrio y antuso, entre los detectados). Igualmente el estudio del influjo de algunos sufijos gentilicios poco productivos de otras lenguas o de difusión localizada, como el -arra y-tarra vascuence y el-eca,-teca $\mathrm{u}$-teco náhuatl. Asimismo, para el caso de los gentilicios de Chile, hemos tomado como corpus el texto de Kordic y Ferreccio 2014. Como este se basó en encuestas dialectales, los autores fueron cuidadosos al indicar cuál es el gentilicio vigente, así como la coexistencia de otros gentilicios o de gentilicios sugeridos por los informantes, en casos, por ejemplo, en que no haya gentilicio vigente o por alguna razón que este estime necesaria. Esta última información, tan relevante como delicada (no sabemos con certeza cuánto hay de imposición o de innovación), la señalamos en la tabla.

\begin{tabular}{|c|c|c|c|c|}
\hline Sufijo & Gentilicio & $\begin{array}{l}\text { Gentilicio en } \\
\text { Chile }\end{array}$ & Observaciones & $\begin{array}{l}\text { Referencias } \\
\text { bibliográficas }\end{array}$ \\
\hline -acho/a & $\begin{array}{l}\text { Mora }(\text { Toledo })> \\
\text { moracho }\end{array}$ & - & $\begin{array}{l}\text { Poco empleado (cfr. } \\
\text { García Sánchez 2005). }\end{array}$ & $\begin{array}{l}\text { García Sánchez } \\
2005 .\end{array}$ \\
\hline -(i/í)aco & $\left|\begin{array}{l}\text { Austria } \\
\text { austriaco, } \\
\text { austríaco } \\
\text { Egipto > egipcíaco } \\
\text { (p.u.) } \\
\text { Morlaquia > } \\
\text { morlaco } \\
\text { Polonia }>\text { polaco }\end{array}\right|$ & $\begin{array}{l}\text { Homónimo: } \\
\text { Quebrada } \\
\text { Quitallaco > } \\
\text { quitallaco } \\
\text { Remoquete: } \\
\text { San Luis > } \\
\text { chalaco }\end{array}$ & $\begin{array}{l}\text { Poca funcionalidad } \\
\text { en la zona de Aragón, } \\
\text { Navarra y La Rioja (cfr. } \\
\text { Garcés Gómez } 1988 \text { en } \\
\text { los datos recabados en } \\
\text { el ALEANR). } \\
\text { Posee, además, un } \\
\text { sentido peyorativo o } \\
\text { jocoso, sobre todo, en } \\
\text { remoquetes (cfr. García } \\
\text { Padrón 2012). }\end{array}$ & $\begin{array}{l}\text { Alemany 1920, } \\
\text { Garcés Gómez } \\
\text { 1988, Ferreccio } \\
\text { y Jocelin } \\
\text { 1992, Rainer } \\
\text { 1999, Nueva } \\
\text { Gramática } \\
\text { 2009, Morera } \\
\text { 2011b, García } \\
\text { Padrón 2012. }\end{array}$ \\
\hline$-\mathrm{al}$ & $\begin{array}{l}\text { Provenza } \\
\text { provenzal }\end{array}$ & $\begin{array}{l}\text { Los Pinos }> \\
\text { pinal }\end{array}$ & Rarísimo en gentilicios. & $\begin{array}{l}\text { Ferreccio y } \\
\text { Jocelin } 1992, \\
\text { Rainer } 1999 .\end{array}$ \\
\hline -án/-ana & $\begin{array}{l}\text { Alemán } \\
\text { Alemania) } \\
\text { Catalán } \\
\text { Cataluña })\end{array}$ & $\begin{array}{l}\text { Las Lumas > } \\
\text { lumán } \\
\text { Punta Delgada } \\
>\text { delgán } \\
\text { Remoquete: } E l \\
\text { Almendro }> \\
\text { bacán }\end{array}$ & $\begin{array}{l}\text { Alemán y catalán, } \\
\text { sin embargo, al ser } \\
\text { étnicos, no deberían } \\
\text { formar parte del elenco } \\
\text { de sufijos gentilicios } \\
\text { en postoponímicos, } \\
\text { empero, han servido } \\
\text { de base para la } \\
\text { construcción de otros }\end{array}$ & $\begin{array}{l}\text { Alemany } 1920, \\
\text { Ferreccio y } \\
\text { Jocelin } 1992, \\
\text { Rainer } 1999 .\end{array}$ \\
\hline
\end{tabular}




\begin{tabular}{|c|c|c|c|c|}
\hline & & & $\begin{array}{l}\text { gentilicios } \\
\text { postoponímicos. } \\
\text { Catalán se entiende } \\
\text { como alomorfo de } \\
\text {-ano, lo mismo que } \\
\text { el desusado castellán } \\
\text { y alemán, todos } \\
\text { apócopes (cfr. Alemany } \\
\text { 1920, Ferreccio y } \\
\text { Jocelin 1992). }\end{array}$ & $\begin{array}{l}\text { Alemany } 1920, \\
\text { Ferreccio y } \\
\text { Jocelin } 1992, \\
\text { Rainer } 1999 . \\
\\
\end{array}$ \\
\hline -anco/a & $\begin{array}{l}\text { Poyales del hoyo } \\
>\text { hoyanco }\end{array}$ & $\begin{array}{l}\text { Remoquete: } \\
\text { Loanzana > } \\
\text { chiguanco }\end{array}$ & $\begin{array}{l}\text { Sumamente raro, } \\
\text { afirma Rainer } 1999 .\end{array}$ & Rainer 1999. \\
\hline -ango/a & $\begin{array}{l}\text { Zudaire > } \\
\text { zudairango }\end{array}$ & - & $\begin{array}{l}\text { De origen germánico } \\
\text { (Garcés Gómez } \\
\text { 1988:1688). }\end{array}$ & $\begin{array}{l}\text { Garcés Gómez } \\
1988 .\end{array}$ \\
\hline $\begin{array}{l}*_{\text {_-(i) }} \\
\text { ano/a }\end{array}$ & $\begin{array}{l}\text { La Rioja > } \\
\text { riojano } \\
\text { Washington > } \\
\text { washingtoniano }\end{array}$ & $\begin{array}{l}\text { Antuco > } \\
\text { antucano } \\
\text { Artificio Alto } \\
>\text { artificiano } \\
\text { Curicó > } \\
\text { curicano } \\
\text { María } \\
\text { Esperanza > } \\
\text { mariano } \\
\text { Las Tablas > } \\
\text { tabliano }\end{array}$ & $\begin{array}{l}\text { Uno de los sufijos más } \\
\text { antiguos y prolíficos } \\
\text { (cfr. Morera 2011 a } \\
\text { b, 2015). De allí la } \\
\text { mayor frecuencia } \\
\text { en atlas lingüísticos } \\
\text { como el ALEANR. Sin } \\
\text { embargo, se detectan } \\
\text { diferencias diatópicas. } \\
\text { Por ejemplo no es el } \\
\text { sufijo gentilicio más } \\
\text { frecuente detectado } \\
\text { en el ALEA o en el } \\
\text { ALEICan solo se } \\
\text { presenta en un punto } \\
\text { (garafiano), cfr. } \\
\text { Garcés Gómez } 1988 \\
\text { y García Sánchez } \\
\text { 2005. Algunos autores } \\
\text { (Nueva Gramática } \\
\text { 2009) consideran } \\
\text { el sufijo -iano/a } \\
\text { independiente, raro, } \\
\text { pero con formaciones } \\
\text { recientes. }\end{array}$ & $\begin{array}{l}\text { Alemany } 1920, \\
\text { Garcés Gómez } \\
1988, \text { Ferreccio } \\
\text { y Jocelin } 1992, \\
\text { Rainer } 1999, \\
\text { Valdivieso y } \\
\text { Soto-Barba } \\
\text { 2002, García } \\
\text { Sánchez 2005, } \\
\text { Ferreccio } \\
\text { 2006, Nueva } \\
\text { Gramática } \\
\text { 2009, Morera } \\
\text { 2011 a y b, } \\
\text { Morera 2015. }\end{array}$ \\
\hline $\begin{array}{l}\text {-ardo/- } \\
\text { arda }\end{array}$ & $\begin{array}{l}\text { Lombardia > } \\
\text { lombardo } \\
\text { Niza }>\text { nizardo } \\
\text { Picardía > } \\
\text { picardo }\end{array}$ & - & $\begin{array}{l}\text { Rainer } 1999 \text { menciona } \\
\text { nizardo como el único } \\
\text { de este grupo. }\end{array}$ & $\begin{array}{l}\text { Alemany } 1920, \\
\text { Rainer } 1999 .\end{array}$ \\
\hline
\end{tabular}




\begin{tabular}{|c|c|c|c|c|}
\hline -ario/a & $\begin{array}{l}\text { Calcena } \\
\text { (Zaragoza) } \\
\text { calcenario (tb. } \\
\text { calcenero) } \\
\text { Mercedes } \\
\text { (Uruguay) > } \\
\text { mercedario } \\
\text { Trinidady Tobago } \\
>\text { trinitario }(\mathrm{tb} . \\
\text { trinitense) }\end{array}$ & $\begin{array}{l}\text { El Culenar > } \\
\text { culenario } \\
\text { La Mercedes } \\
>\text { mercedario } \\
\text { Sucesión } \\
\text { Camino de } \\
\text { Santa Cruz > } \\
\text { sancruzario }\end{array}$ & $\begin{array}{l}\text { Usos secundarios y de } \\
\text { poca frecuencia (cfr. } \\
\text { Garcés Gómez 1988, } \\
\text { Rainer 1999). }\end{array}$ & $\begin{array}{l}\text { Garcés Gómez } \\
\text { 1988, Rainer } \\
1999 .\end{array}$ \\
\hline -arra & $\begin{array}{l}\text { Donostia }> \\
\text { donostiarra } \\
\text { Zarauz > } \\
\text { Zarauztarra }\end{array}$ & - & $\begin{array}{l}\text { Poco usado. Tiene una } \\
\text { clara especialización } \\
\text { geográfica: gentilicios } \\
\text { vascos. }\end{array}$ & $\begin{array}{l}\text { Ferreccio y } \\
\text { Jocelin 1992, } \\
\text { Rainer 1999, } \\
\text { García Sánchez } \\
\text { 2005. }\end{array}$ \\
\hline -asco/a & $\begin{array}{l}\text { Bérgamo } \\
\text { bergamasco }\end{array}>$ & - & $\begin{array}{l}\text { Solo hay dos } \\
\text { formaciones } \\
\text { bergamasco y } \\
\text { monegasco (cfr. Rainer } \\
\text { 1999). }\end{array}$ & $\begin{array}{l}\text { Alemany } 1920, \\
\text { Ferreccio y } \\
\text { Jocelin 1992, } \\
\text { Rainer } 1999 .\end{array}$ \\
\hline -ata & $\begin{array}{l}\text { Crotona } \\
\text { crotoniata } \\
\text { Esparta }> \\
\text { espartiata }(\text { tb. } \\
\text { espartano) } \\
\text { Kenia }>\text { keniata } \\
\text { (junto con } \\
\text { keniano) }\end{array}$ & - & $\begin{array}{l}\text { Rainer } 1999 \text { solo } \\
\text { presenta keniata como } \\
\text { única posibilidad. }\end{array}$ & $\begin{array}{l}\text { Ferreccio } \\
\text { y Jocelin } \\
\text { 1992, Rainer } \\
\text { 1999, Nueva } \\
\text { Gramática } \\
\text { 2009, Morera } \\
\text { 2011 b, Morera } \\
\text { 2015. }\end{array}$ \\
\hline -ato/a & $\begin{array}{l}\text { Jimena de la } \\
\text { Frontera }> \\
\text { jimenato } \\
\text { Chiva }(\text { Valencia })> \\
\text { chivato }(\mathrm{tb} . \\
\text { chivano) } \\
\text { Villar del Ciervo } \\
(\text { Salamanca) > } \\
\text { cervato }\end{array}$ & - & $\begin{array}{l}\text { Usos secundarios para } \\
\text { Rainer } 1999 .\end{array}$ & $\begin{array}{l}\text { Garcés Gómez } \\
\text { 1988, Ferreccio } \\
\text { y Jocelin 1992, } \\
\text { Rainer } 1999 .\end{array}$ \\
\hline $\begin{array}{l}\text {-dán } \\
\text { /-dana }\end{array}$ & $\begin{array}{l}\text { Berga }(\text { Cataluña })> \\
\text { bergadán }\end{array}$ & - & $\begin{array}{l}\text { Al parecer, único caso } \\
\text { es el mencionado por } \\
\text { Ferreccio y Jocelin } \\
1992 .\end{array}$ & $\begin{array}{l}\text { Ferreccio y } \\
\text { Jocelin } 1992 .\end{array}$ \\
\hline
\end{tabular}




\begin{tabular}{|c|c|c|c|c|}
\hline -eco/-a & $\begin{array}{l}\text { Ahuachapán > } \\
\text { ahuachapaneco } \\
\text { Copán>copaneco } \\
\text { Otompán > } \\
\text { otompaneco } \\
\text { SantaAna > } \\
\text { Santaneco }\end{array}$ & $\mid \begin{array}{l}\text { Chope } \\
\text { chopeco }\end{array}$ & $\begin{array}{l}\text { Se asocia generalmente } \\
\text { el sufijo - eco/-eca con } \\
\text { el sufijo náhuatl -ic o-- } \\
\text { tic (cfr. Rainer 1999, } \\
\text { Nueva Gramática } \\
\text { 2009). }\end{array}$ & $\begin{array}{l}\text { Ferreccio } \\
\text { y Jocelin } \\
\text { 1992, Rainer } \\
\text { 1999, Nueva } \\
\text { Gramática } \\
\text { 2009, Morera } \\
\text { 2011 b. }\end{array}$ \\
\hline -ego/a & $\begin{array}{l}\text { Galicia }>\text { gallego } \\
\text { La Mancha > } \\
\text { manchego }\end{array}$ & $\begin{array}{l}\text { Isla de Maipo } \\
>\text { islego } \\
\text { Lo Palacio > } \\
\text { palaciego }\end{array}$ & & $\begin{array}{l}\text { Alemany } 1920, \\
\text { Ferreccio } \\
\text { y Jocelin } \\
\text { 1992, Rainer } \\
\text { 1999, Nueva } \\
\text { Gramática } \\
\text { 2009. }\end{array}$ \\
\hline -ejo/a & $\begin{array}{l}\text { El Villar de } \\
\text { Arnedo (La } \\
\text { Rioja, España)> } \\
\text { villarejo } \\
\text { Popayán > } \\
\text { popayanejo (tb. } \\
\text { payanés) } \\
\text { Caín de Valdeón } \\
\text { (León) > cainejo }\end{array}$ & \begin{tabular}{|l|} 
Angachilla $>$ \\
angachillanejo \\
Chillán $>$ \\
chillanejo
\end{tabular} & $\begin{array}{l}\text { Normalmente se utiliza } \\
\text { como diminutivo } \\
\text { con un cierto matiz } \\
\text { despectivo (cfr. Garcés } \\
\text { Gómez1988) y su uso } \\
\text { en gentilicios es escaso } \\
\text { (cfr. Rainer 1999). } \\
\text { Alomorfo idiosincrático, } \\
\text { lo tipologizan } \\
\text { Valdivieso y Soto-Barba } \\
\text { 2002 para Chile. }\end{array}$ & $\begin{array}{l}\text { Garcés Gómez } \\
1988, \text { Ferreccio } \\
\text { y Jocelin 1992, } \\
\text { Valdivieso y } \\
\text { Soto-Barba } \\
2002 . \\
\\
\end{array}$ \\
\hline -enco & $\begin{array}{l}\text { Ibiza }>\text { ibicenco } \\
\text { Jijona }>\text { jijonenco } \\
\text { Valle de Salazar } \\
\text { (Navarra) > } \\
\text { salacenco }\end{array}$ & $\begin{array}{l}\text { Lo Cruzat } \\
\text { cruzatenco }\end{array}$ & $\begin{array}{l}\text { De escasa frecuencia } \\
\text { (cfr. García Sánchez } \\
\text { 2005). }\end{array}$ & $\begin{array}{l}\text { Alemany } 1920, \\
\text { Ferreccio y } \\
\text { Jocelin } 1992, \\
\text { Rainer } 1999, \\
\text { Morera } 2011 \text { b. }\end{array}$ \\
\hline -eno/a & $\begin{array}{l}\text { Antioquía }(\text { Siria) } \\
>\text { antioqueno } \\
\text { Damasco }> \\
\text { damasceno } \\
\text { Nacianzo }> \\
\text { nacianceno }\end{array}$ & $\begin{array}{l}\text { Chile }> \\
\text { chileno } \\
\text { Lolorruca }> \\
\text { lolorruqueno } \\
\text { Los Niches }> \\
\text { nicheno }\end{array}$ & $\begin{array}{l}\text { A pesar de ser } \\
\text { considerado } \\
\text { sumamente raro (cfr. } \\
\text { Rainer 1999), la Nueva } \\
\text { Gramática lo incluye } \\
\text { en segundo lugar. } \\
\text { Valdivieso y Soto-Barba } \\
\text { 2002 lo consideran un } \\
\text { alomorfo idiosincrático } \\
\text { para Chile. }\end{array}$ & $\begin{array}{l}\text { Alemany } 1920, \\
\text { Ferreccio y } \\
\text { Jocelin } 1992, \\
\text { Rainer } 1999, \\
\text { Valdivieso y } \\
\text { Soto-Barba } \\
\text { 2002, Nueva } \\
\text { Gramática } \\
\text { 2009. }\end{array}$ \\
\hline
\end{tabular}




\begin{tabular}{|c|c|c|c|c|}
\hline $\begin{array}{l}* \text {-(i) } \\
\text { ense }\end{array}$ & $\begin{array}{l}\text { Buenos Aires > } \\
\text { bonaerense } \\
\text { Chihuahua }> \\
\text { chihuahuense } \\
\text { Córdoba }> \\
\text { cordubense } \\
\text { Londres }> \\
\text { londinense } \\
\text { Nicaragua }> \\
\text { nicaragüense } \\
\\
\text { Atenas }> \\
\text { ateniense }\end{array}$ & $\begin{array}{l}\text { Los Pinares > } \\
\text { pinarense } \\
\text { Los } \\
\text { Planchados > } \\
\text { planchesense } \\
\text { La Serena > } \\
\text { serenense }\end{array}$ & 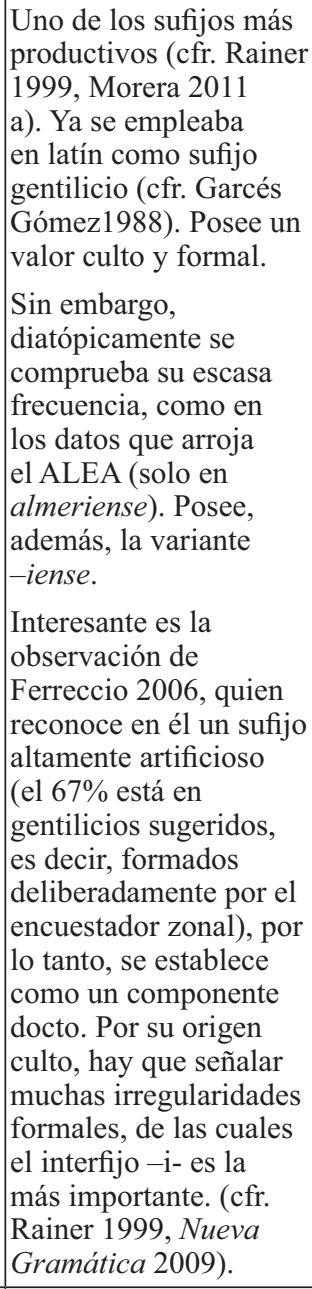 & $\begin{array}{l}\text { Alemany 1920, } \\
\text { Garcés Gómez } \\
\text { 1988, Ferreccio } \\
\text { y Jocelin 1992, } \\
\text { Rainer 1999, } \\
\text { Valdivieso y } \\
\text { Soto-Barba } \\
\text { 2002, García } \\
\text { Sánchez 2005, } \\
\text { Ferreccio } \\
\text { 2006, Nueva } \\
\text { Gramática } \\
\text { 2009, Morera } \\
\text { 2011 a y b, } \\
\text { Morera 2015. } \\
\end{array}$ \\
\hline *-eño/a & $\begin{array}{l}\text { Arcos de Salinas } \\
>\text { argueño } \\
\text { Cáceres }> \\
\text { cacereño }(\mathrm{tb} . \\
\text { norbiense) } \\
\text { Arequipa > } \\
\text { arequipeño } \\
\text { Brasil }>\text { brasileño }\end{array}$ & $\begin{array}{l}\text { Los Placeres } \\
>\text { placeño } \\
\text { Lourdes }> \\
\text { lurdeño } \\
\text { Luma } \\
\text { Mahuida > > } \\
\text { lumeño }\end{array}$ & $\begin{array}{l}\text { Uno de los sufijos } \\
\text { más productivos } \\
\text { (cfr. Morera } 2011 \text { a). } \\
\text { Tal como describe } \\
\text { Garcés Gómez } 1988, \\
\text { diatópicamente se } \\
\text { observan diferencias, } \\
\text { por ejemplo, en el } \\
\text { ALEA es el sufijo }\end{array}$ & $\begin{array}{l}\text { Alemany 1920, } \\
\text { Garcés Gómez } \\
\text { 1988, Ferreccio } \\
\text { y Jocelin 1992, } \\
\text { Rainer 1999, } \\
\text { Valdivieso y } \\
\text { Soto-Barba } \\
\text { 2002, García } \\
\text { Sánchez 2005, }\end{array}$ \\
\hline
\end{tabular}




\begin{tabular}{|c|c|c|c|c|}
\hline & $\begin{array}{l}\text { Carabobo > } \\
\text { carabobeño, } \\
\text { Guayaquil > } \\
\text { guayaquileño } \\
\text { Madrid > } \\
\text { madrileño } \\
\text { Puerto Rico > } \\
\text { puertorriqueño }\end{array}$ & $\begin{array}{l}\text { Pica > }> \\
\text { piqueño } \\
\text { Los Quilos > } \\
\text { quibeño }\end{array}$ & $\begin{array}{l}\text { predominante en casi } \\
\text { todas las provincias } \\
\text { andaluzas frente al } \\
\text { ALEICan, en donde } \\
\text { solo se presenta un } \\
\text { caso (tijarafeño). } \\
\text { Asimismo, es frecuente } \\
\text { en América Latina. Su } \\
\text { productividad actual } \\
\text { se muestra, además, } \\
\text { en formaciones } \\
\text { recientes con bases } \\
\text { no-hispanas: angoleño, } \\
\text { mozambiqueño, } \\
\text { ugandeño, zaireño } \\
\text { (cfr. Rainer 1999). Se } \\
\text { suele afirmar que es el } \\
\text { sufijo usual del norte } \\
\text { de Chile (Oroz 1934 } \\
\text { y 1966), sin embargo, } \\
\text { Ferreccio 2006 señala } \\
\text { que esta frecuencia es } \\
\text { solo aparente, puesto } \\
\text { que el 83\% de los } \\
\text { casos corresponde a } \\
\text { gentilicios sugeridos. }\end{array}$ & $\begin{array}{l}\text { Ferreccio } \\
\text { 2006, Nueva } \\
\text { Gramática } \\
\text { 2009, Morera } \\
2011 \text { b, Morera } \\
2015 . \\
\\
\\
\end{array}$ \\
\hline -eo/a & $\begin{array}{l}\text { Cirene }>\text { cireneo } \\
\text { Europa }>\text { europeo }\end{array}$ & - & $\begin{array}{l}\text { Sobre todo en étnicos } \\
\text { (caldeo, cananeo), de } \\
\text { tradición clásica (cfr. } \\
\text { Alemany 1920). }\end{array}$ & $\begin{array}{l}\text { Alemany } \\
\text { 1920, Rainer } \\
\text { 1999, Nueva } \\
\text { Gramática } \\
2009 .\end{array}$ \\
\hline -ero/a & $\begin{array}{l}\text { La Habana > } \\
\text { habanero } \\
\text { Salinas de Oro } \\
\text { (Navarra) > } \\
\text { salinero } \\
\text { Pallaruelo } \\
\text { de Monegros } \\
\text { (Huesca) > } \\
\text { pallaruelero } \\
\text { Sos del Rey } \\
\text { Católico (Aragón) } \\
>\text { sosero }\end{array}$ & $\begin{array}{l}\text { Cachantún > } \\
\text { cachantunero } \\
\text { Caleta } \\
\text { Chipana > } \\
\text { chipanero } \\
\text { Remoquetes: } \\
\text { Agua Fría > } \\
\text { pelillero } \\
\text { Almendral > } \\
\text { cuatrero } \\
\text { Ancud > } \\
\text { muñero }\end{array}$ & $\begin{array}{l}\text { Uno de los sufijos más } \\
\text { nuevos (cfr. Morera } \\
2011 \text { a, Rainer 1999, } \\
\text { quienes dan cuenta de } \\
\text { su aparición, sobre todo } \\
\text { en Andalucía, Canarias } \\
\text { y América Latina). } \\
\text { Diatópicamente, es } \\
\text { el segundo sufijo } \\
\text { gentilicio que se } \\
\text { presenta en ALEA. } \\
\text { En ALEICan es el } \\
\text { sufijo gentilicio más } \\
\text { empleado (cfr. Garcés } \\
\text { Gómez 1988). }\end{array}$ & $\begin{array}{l}\text { Alemany } 1920, \\
\text { Garcés Gómez } \\
1988, \text { Ferreccio } \\
\text { y Jocelin } \\
1992, \text { Rainer } \\
\text { 1999, Nueva } \\
\text { Gramática } \\
\text { 2009, Morera } \\
\text { 2011 a y b, } \\
\text { Morera 2015. }\end{array}$ \\
\hline
\end{tabular}




\begin{tabular}{|c|c|c|c|c|}
\hline -és/a & $\begin{array}{l}\text { Berlín }>\text { berlinés } \\
\text { Bután }>\text { butanés } \\
\text { Francia }>\text { francés } \\
\text { Holanda }> \\
\text { holandés } \\
\text { Japón }>\text { japonés }\end{array}$ & $\begin{array}{l}\text { Catalina > > } \\
\text { catalinés } \\
\text { El Barón > } \\
\text { baronés } \\
\text { Las garzas > } \\
\text { Garcés } \\
\text { Mallín Grande } \\
>\text { mallinés } \\
\text { Remoquetes: } \\
\text { Cayurranquil } \\
>\text { montañés }\end{array}$ & $\begin{array}{l}\text { Derivado del sufijo } \\
\text { latino - ensis, que } \\
\text { también se empleaba } \\
\text { para crear gentilicios. } \\
\text { Contiende con la } \\
\text { variante culta - ense, } \\
\text { siendo -és la más } \\
\text { usual. } \\
\text { (cfr. Alemany } 1920 \\
\text { y Garcés Gómez } \\
\text { 1988). Rainer } 1999 \\
\text { observa que, si bien } \\
\text { es usual en el norte } \\
\text { de España, no lo es } \\
\text { en América Latina. } \\
\text { Su productividad } \\
\text { se comprueba } \\
\text { con gentilicios } \\
\text { relativamente nuevos, } \\
\text { como asamés, } \\
\text { camerunés, ghanés, } \\
\text { katangués, entre otros. }\end{array}$ & $\begin{array}{l}\text { Alemany 1920, } \\
\text { Garcés Gómez } \\
1988, \text { Ferreccio } \\
\text { y Jocelin 1992, } \\
\text { Rainer 1999, } \\
\text { Valdivieso y } \\
\text { Soto-Barba } \\
\text { 2002, Ferreccio } \\
\text { 2006, Nueva } \\
\text { Gramática } \\
\text { 2009, Morera } \\
\text { 2011 b, Morera } \\
2015 \text {. }\end{array}$ \\
\hline -esco/a & $\mid \begin{array}{l}\text { El Toboso > } \\
\text { tobosesco (obs.) } \\
\text { Irlanda > } \\
\text { irlandesco (obs.) } \\
\text { Turquía > } \\
\text { turquesco } \\
\text { Versalles > } \\
\text { versallesco }\end{array}$ & $\begin{array}{l}\text { Illanes > > } \\
\text { illanesco } \\
\text { (sugerido por } \\
\text { el informante) }\end{array}$ & $\begin{array}{l}\text { De baja frecuencia } \\
\text { y muchos de ellos } \\
\text { obsolescentes. } \\
\text { Además, muchos de } \\
\text { ellos relacionados } \\
\text { más bien con aspectos } \\
\text { [-humano]. }\end{array}$ & $\begin{array}{l}\text { Alemany } 1920, \\
\text { Rainer } 1999, \\
\text { Morera } 2011 \text { b. }\end{array}$ \\
\hline -eta & $\begin{array}{l}\text { Lisboa }>\text { lisboeta } \\
\text { Egina }>\text { egineta }\end{array}$ & - & & $\begin{array}{l}\text { Ferreccio } \\
\text { y Jocelin } \\
\text { 1992, Rainer } \\
\text { 1999, Nueva } \\
\text { Gramática } \\
\text { 2009, Morera } \\
\text { 2011 b, Morera } \\
\text { 2015. }\end{array}$ \\
\hline -ete & $\begin{array}{l}\text { Miguel Esteban } \\
\text { (Toledo) > } \\
\text { miguelete }\end{array}$ & $\begin{array}{l}\text { Remoquetes: } \\
\text { La Cañamera } \\
\text { > cañete }\end{array}$ & & $\begin{array}{l}\text { Ferreccio y } \\
\text { Jocelin 1992, } \\
\text { Ferreccio 2006. }\end{array}$ \\
\hline
\end{tabular}




\begin{tabular}{|c|c|c|c|c|}
\hline -í & $\begin{array}{l}\text { Irán }>\text { iraní } \\
\text { Marruecos }> \\
\text { marroqui }\end{array}$ & $\mid \begin{array}{l}\text { Capellanía > } \\
\text { capellani } \\
\text { (sugerido) }\end{array}$ & \begin{tabular}{|l|} 
Formante recurrente, \\
pero restringido \\
a gentilicios de \\
origen semítico (cfr. \\
Ferreccio y Jocelin \\
1992, Rainer 1999). \\
Sigue, empero, siendo \\
productivo (kuwaití, \\
omaní, bangladeshi). \\
Asimismo coincide \\
con étnicos indígenas \\
americanos (calchaqui, \\
guaraní, querandi, \\
arañi) y con gentilicios \\
catalanes (mallorquí, \\
barceloni, gironi, olotí, \\
tortosi). (cfr. Ferreccio \\
y Jocelin 1992).
\end{tabular} & $\begin{array}{l}\text { Alemany 1920, } \\
\text { Garcés Gómez } \\
\text { 1988, Ferreccio } \\
\text { y Jocelin } \\
\text { 1992, Rainer } \\
\text { 1999, Nueva } \\
\text { Gramática } \\
\text { 2009, García } \\
\text { Sánchez 2005, } \\
\text { Morera 2011 b, } \\
\text { Morera 2015. }\end{array}$ \\
\hline- ica & $\begin{array}{l}\text { Pamplona > } \\
\text { pamplonica }\end{array}$ & - & $\begin{array}{l}\text { Garcés Gómez } 1988 \\
\text { sugiere la posibilidad } \\
\text { de una connotación } \\
\text { burlesca. Para Rainer } \\
1999 \text { es un uso } \\
\text { secundario. }\end{array}$ & $\begin{array}{l}\text { Garcés Gómez } \\
\text { 1988, Rainer } \\
1999 .\end{array}$ \\
\hline -icho & $\begin{array}{l}\text { Bornos }(\text { Cádiz })> \\
\text { bornicho }\end{array}$ & - & & $\begin{array}{l}\text { Ferreccio y } \\
\text { Jocelin } 1992 .\end{array}$ \\
\hline -`ico/a & $\begin{array}{l}\text { Hispania }> \\
\text { hispánico } \\
\text { Jonia }>\text { jónico } \\
\text { Libia }>\text { líbico }\end{array}$ & $\begin{array}{l}\text { Los Pozos > } \\
\text { posaico } \\
\text { (sugerido) } \\
\text { Santa Helena } \\
>\text { helénico } \\
\text { Polhuín > } \\
\text { polhuínico }\end{array}$ & $\begin{array}{l}\text { Parece ser un sufijo } \\
\text { no productivo en la } \\
\text { actualidad pero que } \\
\text { forma parte de una } \\
\text { serie de formaciones } \\
\text { usuales: Asia/asiático, } \\
\text { balcánico, baleárico, } \\
\text { caucásico, libico, } \\
\text { patagónico, etc. (cfr. } \\
\text { Rainer 1999). }\end{array}$ & $\begin{array}{l}\text { Rainer 1999, } \\
\text { Morera } 2011 \\
\text { a y b. }\end{array}$ \\
\hline -iego/a & $\begin{array}{l}\text { Bonares > } \\
\text { bonariego } \\
\text { Castellar > } \\
\text { castellariego } \\
\text { Liébana > } \\
\text { lebaniego } \\
\text { Los Villares > } \\
\text { Villadiego }\end{array}$ & $\mid \begin{array}{l}\text { Lo Palacio }> \\
\text { palaciego }\end{array}$ & \begin{tabular}{|l|} 
Para algunos \\
autores es un sufijo \\
iberorromance, de \\
origen vasco o b́bérico \\
(cfr. Garcés Gómez \\
1988) de escasa \\
productividad gentilicia \\
(cfr. Rainer 1999).
\end{tabular} & $\begin{array}{l}\text { Alemany 1920, } \\
\text { Garcés Gómez } \\
1988, \text { Ferreccio } \\
\text { y Jocelin 1992, } \\
\text { Rainer 1999, } \\
\text { García Sánchez } \\
\text { 2005, Morera } \\
\text { 2011 b. }\end{array}$ \\
\hline
\end{tabular}




\begin{tabular}{|c|c|c|c|c|}
\hline & $\mid \begin{array}{l}\text { Navia }>\text { naviego } \\
\text { Sierra de Gata }> \\
\text { serraniego } \\
\text { Valle Pas }> \\
\text { pasiego } \\
\text { Vejer de la } \\
\text { Frontera }> \\
\text { vejeriego }\end{array}$ & & & \\
\hline -ién & París > parisién & - & $\begin{array}{l}\text { Al parecer, solo en } \\
\text { parisién. }\end{array}$ & Rainer 1999. \\
\hline - 'igo & Árabe $>$ arábigo & - & $\begin{array}{l}\text { Al parecer solo en } \\
\text { arábigo. }\end{array}$ & Rainer 1999. \\
\hline -ijo/a & $\begin{array}{l}\text { Santibáñez El } \\
\text { Bajo > santibañijo } \\
(\text { o santibajeño) }\end{array}$ & - & $\begin{array}{l}\text { Al parecer solo en } \\
\text { santibañijo. }\end{array}$ & Rainer 1999. \\
\hline -ín/a & $\begin{array}{l}\text { Mallorca } \\
\text { mallorquín }\end{array}$ & $\begin{array}{l}\text { Gualte > } \\
\text { gualtín (tb. } \\
\text { gualtino y } \\
\text { gualteño) } \\
\text { La Verdina }> \\
\text { verdin } \\
\text { (sugerido) }\end{array}$ & $\begin{array}{l}\text { De escasa frecuencia, } \\
\text { se encuentra, sobre } \\
\text { todo, en Cataluña. }\end{array}$ & $\begin{array}{l}\text { Rainer } \\
\text { 1999, Nueva } \\
\text { Gramática } \\
2009 .\end{array}$ \\
\hline *-ino/a & $\begin{array}{l}\text { Argelia }>\text { argelino } \\
\text { Florencia > } \\
\text { florentino } \\
\text { Granada }> \\
\text { granadino } \\
\text { New York }> \\
\text { neoyorkino }\end{array}$ & $\mid \begin{array}{l}\text { Aconcagua > } \\
\text { aconcagüino } \\
\text { Maule > } \\
\text { maulino } \\
\text { Quilquén > } \\
\text { quilquenino }\end{array}$ & $\begin{array}{l}\text { Uno de los sufijos más } \\
\text { antiguos y prolíficos } \\
\text { (cfr. Morera } 2011^{\text {a }} \text {, en } \\
\text { tercer lugar lo incluye } \\
\text { la Nueva Gramática } \\
\text { 2009). Es el más usual } \\
\text { en Chile (cfr. Oroz } \\
\text { 1966, Valdivieso y } \\
\text { Soto-Barba 2002, } \\
\text { Ferreccio 2006), por lo } \\
\text { que pasa a ser el } \\
\text { alomorfo general y } \\
\text { la forma no marcada } \\
\text { (Valdivieso y Soto- } \\
\text { Barba 2002). }\end{array}$ & $\begin{array}{l}\text { Alemany 1920, } \\
\text { Oroz 1966, } \\
\text { Garcés Gómez } \\
\text { 1988, Ferreccio } \\
\text { y Jocelin 1992, } \\
\text { Rainer 1999, } \\
\text { Valdivieso y } \\
\text { Soto-Barba } \\
\text { 2002, Ferreccio } \\
\text { 2006, Nueva } \\
\text { Gramática } \\
\text { 2009, Morera } \\
\text { 2011 b, Morera } \\
\text { 2015. }\end{array}$ \\
\hline -io/a & $\begin{array}{l}\text { Corinto }>\text { corintio } \\
\text { Egipto }>\text { egipcio } \\
\text { Rodas }>\text { rodio }\end{array}$ & $\begin{array}{l}\text { Villa Trintre }> \\
\text { trintrolio } \\
\text { Rio de la } \\
\text { Colonia }> \\
\text { riocolonio } \\
\text { (sugerido) }\end{array}$ & $\begin{array}{l}\text { Se encuentra en } \\
\text { algunos gentilicios } \\
\text { de Grecia y medio } \\
\text { Oriente, sobre todo } \\
\text { (Rainer 1999). }\end{array}$ & $\begin{array}{l}\text { Ferreccio y } \\
\text { Jocelin 1992, } \\
\text { Rainer 1999, } \\
\text { Morera 2015. }\end{array}$ \\
\hline
\end{tabular}




\begin{tabular}{|c|c|c|c|c|}
\hline -isco & $\begin{array}{l}\text { Llanes (Asturias) } \\
>\text { llanisco }\end{array}$ & - & $\begin{array}{l}\text { Muy raro, observa } \\
\text { Rainer } 1999 .\end{array}$ & $\begin{array}{l}\text { Ferreccio y } \\
\text { Jocelin } 1992, \\
\text { Rainer } 1999 .\end{array}$ \\
\hline -ista & $\begin{array}{l}\text { Ambaca (Angola) } \\
>\text { ambaquista } \\
\text { Santos }>\text { santista } \\
\text { Llera }>\text { llerista } \\
(\text { tb llerense) }\end{array}$ & $\begin{array}{l}\text { Balmaceda } \\
\text { La Junta > } \\
\text { balmacedista } \\
\text { El Progreso > } \\
\text { progresista } \\
\text { Penco } \\
\text { (Concepción) } \\
\text { > penquista }\end{array}$ & \begin{tabular}{|l|} 
Muy raro, observa \\
Rainer 1999. \\
Valdivieso y Soto- \\
Barba 2002 para \\
Chile lo proponen \\
como alomorfo \\
idiosincrático de difícil \\
productividad.
\end{tabular} & $\begin{array}{l}\text { Ferreccio y } \\
\text { Jocelin 1992, } \\
\text { Rainer 1999, } \\
\text { Valdivieso y } \\
\text { Soto-Barba } \\
2002 .\end{array}$ \\
\hline -isto/a & - & $\begin{array}{l}\text { El Rincón > } \\
\text { rinconisto (tb. } \\
\text { rinconino) }\end{array}$ & $\begin{array}{l}\text { Rainer } 1999 \text { señala que } \\
\text { hay pocas formaciones } \\
\text { en América Latina. } \\
\text { Se menciona } \\
\text { un molinisto no } \\
\text { atestiguado. También } \\
\text { un cauquenisto para } \\
\text { Cauquenes, Chile, del } \\
\text { que no hay más datos } \\
\text { que el de un periódico. }\end{array}$ & $\begin{array}{l}\text { Ferreccio y } \\
\text { Jocelin } 1992, \\
\text { Rainer } 1999 . \\
\\
\end{array}$ \\
\hline -ita & $\begin{array}{l}\text { Israel > israelita } \\
\text { Moscú > } \\
\text { moscovita } \\
\text { Arabia Saudi > } \\
\text { saudita }\end{array}$ & - & $\begin{array}{l}\text { Sobre todo en } \\
\text { formaciones } \\
\text { pertenecientes al } \\
\text { Antiguo Oriente. } \\
\text { También hay otras } \\
\text { formaciones, como } \\
\text { moscovita. El uso de } \\
\text {-ita } \text { en vez de }-i \text { en } \\
\text { formaciones de medio } \\
\text { oriente es rechazado } \\
\text { por los puristas (cfr. } \\
\text { Rainer 1999). }\end{array}$ & $\begin{array}{l}\text { Alemany } \\
\text { 1920, Rainer } \\
\text { 1999, Nueva } \\
\text { Gramática } \\
\text { 2009, Morera } \\
\text { 2011 b, Morera } \\
2015 \text {. }\end{array}$ \\
\hline -itano & $\begin{array}{l}\text { Calatayud > } \\
\text { bilbitano } \\
\text { Cádiz > gaditano } \\
\text { Calahorra > } \\
\text { calagurritano } \\
\text { Nápoles > } \\
\text { napolitano } \\
\text { Trípolo > } \\
\text { tripolitano }\end{array}$ & $\mid \begin{array}{l}\text { Ancud > > } \\
\text { ancuditano } \\
\text { Diaguitas > } \\
\text { diaguitano } \\
\text { Lagunitas > } \\
\text { legunitano }\end{array}$ & \begin{tabular}{|l|} 
Este formante \\
latinizante deriva de \\
la serie de topónimos \\
compuestos con \\
polis 'ciudad'. Para \\
Valdivieso y Soto- \\
Barba 2002 sería un \\
alomorfo idiosincrático \\
en Chile.
\end{tabular} & $\begin{array}{l}\text { Ferreccio y } \\
\text { Jocelin 1992, } \\
\text { Valdivieso y } \\
\text { Soto-Barba } \\
\text { 2002, García } \\
\text { Sánchez } 2005 .\end{array}$ \\
\hline
\end{tabular}




\begin{tabular}{|c|c|c|c|c|}
\hline -ito & Jauja $>$ hagüito & $\begin{array}{l}\text { Caracoles }> \\
\text { caracolito } \\
\text { Villa Malal > } \\
\text { malalito } \\
\text { Pamela > } \\
\text { pamelito } \\
\text { (sugerido) }\end{array}$ & $\begin{array}{l}\text { Garcés Gómez } 1988 \\
\text { solo lo detecta en } \\
\text { Jauja }>\text { hagüito, el } \\
\text { que no hemos podido } \\
\text { corroborar. }\end{array}$ & $\begin{array}{l}\text { Garcés Gómez } \\
1988 .\end{array}$ \\
\hline$-\mathrm{o} /-\mathrm{a}$ & $\begin{array}{l}\text { Argentina > } \\
\text { argentino } \\
\text { Birmania > } \\
\text { birmano } \\
\text { Navarra > } \\
\text { navarro } \\
\text { Rusia }>\text { ruso }\end{array}$ & $\begin{array}{l}\text { Catalina }> \\
\text { catalino } \\
\text { Guayún }> \\
\text { Huayuno } \\
\text { La Moranina }> \\
\text { moranino }\end{array}$ & & $\begin{array}{l}\text { Ferreccio } \\
\text { y Jocelin } \\
\text { 1992, Rainer } \\
\text { 1999, Nueva } \\
\text { Gramática } \\
\text { 2009. }\end{array}$ \\
\hline -ol/-ola & España > español & - & $\begin{array}{l}\text { Solo se da en español } \\
\text { y es un sufijo occitano } \\
\text { (cfr. Ferreccio y Jocelin } \\
\text { 1992, Rainer 1999). }\end{array}$ & $\begin{array}{l}\text { Ferreccio } \\
\text { y Jocelin } \\
\text { 1992, Rainer } \\
\text { 1999, Nueva } \\
\text { Gramática } \\
2009 .\end{array}$ \\
\hline -olo & $\begin{array}{l}\text { La Guardia > } \\
\text { guardiolo }\end{array}$ & - & & $\begin{array}{l}\text { Ferreccio y } \\
\text { Jocelin } 1992 .\end{array}$ \\
\hline -ón/a & $\begin{array}{l}\text { Borgoña }> \\
\text { borgoñón } \\
\text { Bravante } \\
\text { bravazón }\end{array}$ & $\begin{array}{l}\text { Penco > > } \\
\text { pencón } \\
\text { Los Bajos }> \\
\text { bajón } \\
\text { (sugerido) } \\
\text { Remoquetes: } \\
\begin{array}{l}\text { Carretones }> \\
\text { chonchón }\end{array}\end{array}$ & $\begin{array}{l}\text { Voces de clara } \\
\text { procedencia } \\
\text { galorrománica, aún } \\
\text { con topónimos que no } \\
\text { son de aquel país (cfr. } \\
\text { Ferreccio y Jocelin } \\
\text { 1992). Al poseer } \\
\text { valor aumentativo en } \\
\text { español, no es un sufijo } \\
\text { gentilicio productivo } \\
\text { (cfr. patagón). Para } \\
\text { Valdivieso y Soto- } \\
\text { Barba 2002 en } \\
\text { Chile sería alomorfo } \\
\text { idiosincrático. }\end{array}$ & $\begin{array}{l}\text { Ferreccio y } \\
\text { Jocelin } 1992, \\
\text { Rainer 1999, } \\
\text { Valdivieso y } \\
\text { Soto-Barba } \\
\text { 2002, Morera } \\
\text { 2011 b, Morera } \\
2015 .\end{array}$ \\
\hline -oso & $\begin{array}{l}\text { Grimaldo > } \\
\text { grimaldoso } \\
\text { Mazalinos > } \\
\text { mazalinoso } \\
\text { La Hoya }>\text { hoyoso } \\
\text { Terrinches > } \\
\text { terrinchoso }\end{array}$ & \begin{tabular}{|l} 
La Gloria > \\
glorioso \\
Río Resbalón \\
$>$ resfaloso \\
Los Barros \\
$>$ barroso \\
(sugerido) \\
Remoquetes: \\
La Dificultad \\
$>$ dificultuoso
\end{tabular} & $\begin{array}{l}\text { Poco usado (García } \\
\text { Sánchez 2005) y } \\
\text { secundario (Rainer } \\
\text { 1999). }\end{array}$ & $\begin{array}{l}\text { Garcés Gómez } \\
\text { 1988, Rainer } \\
\text { 1999, García } \\
\text { Sánchez 2005, } \\
\text { Morera 2015. }\end{array}$ \\
\hline
\end{tabular}




\begin{tabular}{|c|c|c|c|c|}
\hline -ota & $\mid \begin{array}{l}\text { Sologne > } \\
\text { soloñota } \\
\text { Chipre }> \\
\text { chipriota } \\
\text { El Cairo }>\text { cairota } \\
\text { Biarritz > } \\
\text { biarrota }\end{array}$ & $\begin{array}{l}\text { Los Cipreses } \\
>\text { cipriota } \\
\text { (sugerido) }\end{array}$ & $\begin{array}{l}\text { Pocos los gentilicios } \\
\text { (Rainer 1999). }\end{array}$ & $\begin{array}{l}\text { Alemany } 1920, \\
\text { Ferreccio y } \\
\text { Jocelin } 1992, \\
\text { Rainer 1999, } \\
\text { Morera 2011 b, } \\
\text { Morera 2015. }\end{array}$ \\
\hline -ote & & $\begin{array}{l}\text { Chiloé }> \\
\text { chilote }\end{array}$ & $\begin{array}{l}\text { El único gentilicio } \\
\text { en -ote quizá sea } \\
\text { chilote (Rainer } \\
\text { 1999). Valdivieso y } \\
\text { Soto-Barba } 2002 \text { lo } \\
\text { dan como alomorfo } \\
\text { idiosincrásico. }\end{array}$ & $\begin{array}{l}\text { Ferreccio y } \\
\text { Jocelin 1992, } \\
\text { Rainer 1999, } \\
\text { Valdivieso y } \\
\text { Soto-Barba } \\
2002 .\end{array}$ \\
\hline -oto & $\begin{array}{l}\text { Bajo Miño } \\
\text { (Galicia) > miñoto }\end{array}$ & - & & $\begin{array}{l}\text { Ferreccio y } \\
\text { Jocelin } 1992 .\end{array}$ \\
\hline -tán & $\begin{array}{l}\text { Borjas del Campo } \\
\text { (Tarragona) }> \\
\text { borjatán } \\
\text { La Selva } \\
\text { del Campo } \\
\text { (Tarragona) > } \\
\text { selvatán } \\
\text { Vich }>\text { vigatán }\end{array}$ & - & $\begin{array}{l}\text { Ferreccio y Jocelin } \\
1992 \text { postulan que } \\
\text { la hispanización del } \\
\text {-tanus catalanizado } \\
\text { selvatà, borjatà y } \\
\text { vigatà serían selvatán, } \\
\text { borjatán y vigatán. }\end{array}$ & $\begin{array}{l}\text { Ferreccio y } \\
\text { Jocelin } 1992 .\end{array}$ \\
\hline -tarra & $\begin{array}{l}\text { Basauri > } \\
\text { basauritarra }\end{array}$ & - & & $\begin{array}{l}\text { Ferreccio y } \\
\text { Jocelin } 1992 .\end{array}$ \\
\hline -teca & $\begin{array}{l}\text { Quechula > } \\
\text { quechulteca }\end{array}$ & - & & $\begin{array}{l}\text { Ferreccio y } \\
\text { Jocelin } 1992 .\end{array}$ \\
\hline -teco & $\begin{array}{l}\text { Guatemala > } \\
\text { guatemalteco }\end{array}$ & - & & $\begin{array}{l}\text { Ferreccio y } \\
\text { Jocelin } 1992 .\end{array}$ \\
\hline -uano & $\begin{array}{l}\text { Minas (Uruguay) } \\
>\text { minuano }\end{array}$ & $\begin{array}{l}\text { Pichibudis > } \\
\text { pichiguano; } \\
\text { Quinchao > } \\
\text { quinchaguano } \\
\\
\text { Codegua > } \\
\text { codeguano; } \\
\text { Ilochegua < } \\
\text { ilocheguano. }\end{array}$ & $\begin{array}{l}\text { Nos hemos percatado } \\
\text { de que esa vocal } \\
\text { velar tiende a la } \\
\text { consonantización en } \\
\text { muchísimos gentilicios } \\
\text { detectados en Chile, } \\
\text { tanto en topónimos } \\
\text { cuya terminación es en } \\
\text {-gua, como en otros. }\end{array}$ & $\begin{array}{l}\text { Ferreccio y } \\
\text { Jocelin } 1992 .\end{array}$ \\
\hline
\end{tabular}




\begin{tabular}{|c|c|c|c|c|}
\hline -uco & $\begin{array}{l}\text { Salto de } \\
\text { Aldeadávila }> \\
\text { aldeaviluco } \\
\text { Villa de Mazo } \\
\text { (Canarias) > > } \\
\text { mazuco }\end{array}$ & $\begin{array}{l}\text { Pichirrincón } \\
>\text { pichirruco } \\
\text { (sugerido) }\end{array}$ & $\begin{array}{l}\text { Para Rainer } 1999 \text { serían } \\
\text { usos secundarios. }\end{array}$ & $\begin{array}{l}\text { Garcés Gómez } \\
\text { 1988, Ferreccio } \\
\text { y Jocelin 1992, } \\
\text { Rainer } 1999 .\end{array}$ \\
\hline -ucho & $\begin{array}{l}\text { Aguilafuente > } \\
\text { aguilucho }\end{array}$ & $\begin{array}{l}\text { Isla Quenu > } \\
\text { quenucho (tb. } \\
\text { quenuino) }\end{array}$ & $\begin{array}{l}\text { Para Rainer } 1999 \text { serían } \\
\text { usos secundarios. }\end{array}$ & $\begin{array}{l}\text { Garcés Gómez } \\
\text { 1988, Rainer } \\
\text { 1999. }\end{array}$ \\
\hline -ujo/a & $\begin{array}{l}\text { Portugalete } \\
\text { portugalujo }\end{array}>$ & - & $\begin{array}{l}\text { Rainer } 1999 \text { menciona } \\
\text { portugalujo como el } \\
\text { único de este grupo. }\end{array}$ & $\begin{array}{l}\text { Ferreccio y } \\
\text { Jocelin } 1992, \\
\text { Rainer } 1999 .\end{array}$ \\
\hline -uno/a & $\begin{array}{l}\text { Fresno }>\text { fresnuno } \\
\text { Páramo > } \\
\text { paramuno } \\
\text { Valle }>\text { valluno } \\
\text { Villavicencio > } \\
\text { villavicenciuno }\end{array}$ & $\begin{array}{l}\text { Colu }>\text { coluno } \\
\text { Hierro Viejo }> \\
\text { hierruno } \\
\text { Isla Huar > } \\
\text { huaruno } \\
\text { Los Maquis }> \\
\text { macuno }\end{array}$ & $\begin{array}{l}\text { Poco frecuente. } \\
\text { Valdivieso y Soto- } \\
\text { Barba } 2002 \text { afirman } \\
\text { que es un alomorfo } \\
\text { idiosincrático de poca } \\
\text { productividad. }\end{array}$ & $\begin{array}{l}\text { Ferreccio y } \\
\text { Jocelin } 1992, \\
\text { Rainer 1999, } \\
\text { Valdivieso y } \\
\text { Soto-Barba } \\
\text { 2002, Nueva } \\
\text { Gramática } \\
\text { 2009, Morera } \\
\text { 2011 b, Morera } \\
2015 \text {. }\end{array}$ \\
\hline -urrio & $\begin{array}{l}\text { Capileira }> \\
\text { capilurrio }\end{array}$ & - & $\begin{array}{l}\text { Sufijo ibérico con } \\
\text { un matiz despectivo } \\
\text { (Garcés Gómez 1988). } \\
\text { Poco frecuente. }\end{array}$ & $\begin{array}{l}\text { Garcés Gómez } \\
1988 .\end{array}$ \\
\hline -usco/a & $\begin{array}{l}\text { Baño de la Encina } \\
(\text { Jaén) > bañusco } \\
\text { Arenas del Rey } \\
(\text { Granada) > } \\
\text { arenusco (tb. } \\
\text { taranto })\end{array}$ & - & & $\begin{array}{l}\text { Ferreccio y } \\
\text { Jocelin } 1992, \\
\text { Rainer } 1999 .\end{array}$ \\
\hline -uso & $\begin{array}{l}\text { Antas }>\text { antuso } \\
(\mathrm{tb} . \text { antense })\end{array}$ & - & & $\begin{array}{l}\text { Ferreccio y } \\
\text { Jocelin } 1992 .\end{array}$ \\
\hline -uto & $\begin{array}{l}\text { Sallent de Gállego } \\
>\text { sallenuto }\end{array}$ & - & $\begin{array}{l}\text { Al parecer, como } \\
\text { remoquete despectivo. }\end{array}$ & $\begin{array}{l}\text { Garcés Gómez } \\
1988 .\end{array}$ \\
\hline
\end{tabular}




\section{CONCLUSIONES}

Hemos querido presentar, en esta investigación, un aspecto fundamental si queremos iniciar una reflexión crítica acerca del gentilicio, y es la de intentar entregar las directrices generales que sostienen el concepto gentilicio, es decir, la entrega de una suerte de prolegómenos. Por tratarse, sobre todo, de una categoría designativa y por deber abordarla desde un punto de vista enciclopédico, es preciso extenderse a otros aspectos para poder dar cuenta de este concepto desde una óptica arquitectural. Por ahora, nos quedamos solo en estos prolegómenos, basados en el intento de definir al gentilicio desde una perspectiva onomasiológica, es decir, qué es un gentilicio étnico, qué es un gentilicio postoponímico y qué consideraciones semánticas hay que tener en este último caso. También lo hemos abordado desde una perspectiva sintáctica, trayendo a colación el pocas veces tratado sintagma de origen o procedencia territorial, así como nuestro intento de tratar de determinar la función del gentilicio, sobre todo del postoponímico. Asimismo, nos hemos centrado en la perspectiva que más estudios y reflexiones ha dado: la morfológica, sobre todo porque en el proceso derivacional que se genera, presenta una serie de posibilidades interesantísimas si se posee un corpus con el cual trabajarlas. Además, nos centramos en los sufijos mismos: cuáles operan en este proceso derivacional y si se puede hablar, propiamente, de sufijos gentilicios. Asimismo, hemos querido cerrar la investigación con una tabla que muestra los sufijos en lengua española productivos, relativamente productivos y escasamente productivos, haciendo previamente mención a la posible existencia de sufijos hápax, cosa que quedará reservada para algún estudio posterior.

\section{REFERENCIAS BIBLIOGRÁFICAS}

Alarcos Llorach, Emilio. 1974. Gramática estructural. Madrid: Gredos.

Alemany, José. 1920. Tratado de la formación de palabras en la lengua castellana. Madrid: Librería general de Victoriano Suárez.

Almela Pérez, Ramón. 2013. Los sufijos gentilicios: un grupo tan discutible como erróneo, Cálamo FASPE 61: 12-21

Benveniste, Émile 1974 [1999]. Problemas de lingüística general II. Madrid: Siglo XXI editores.

Bosque, Ignacio. 1999. El nombre común. En Bosque, Ignacio y Violeta Demonte (dirs.). Gramática descriptiva de la lengua española. Madrid: Espasa.

Chávez Fajardo, Soledad y Raissa Kordic Riquelme, a. El gentilicio: consideraciones morfológicas. El caso del gentilicio en Chile. En prensa. 
b. Acerca del gentilicio: de historiografía, de remoquetes y de estandarización. En prensa.

Faitelson-Weiser, Silvia. 1981. Les suffixes quantificateurs de l'espagnol. Paris: Editions Hispaniques.

Ferreccio, Mario. 2006. Una singularidad en la formación de los gentilicios: irradiación, cognados y afines. Onomazein 13: 177-189.

Ferreccio, Mario y Jorge Jocelin. 1992. El gentilicio. Identificación de una categoría onomasiológica. Santiago de Chile: Imprenta Irarrázabal.

Garcés Gómez, María Pilar. 1988. La formación de gentilicios en varias zonas españolas. Manuel Ariza, Antonio Salvador, A. Viudas: Actas del I Congreso Internacional de Historia de la Lengua Española, pp. 1685-1696. Madrid: Arco/Libros.

García Gallarín, Consuelo. 2003. Los gentilicios en la historia del español. En J.L. Girón, J. Herrero, et al. Estudios ofrecidos al profesor José Jesús de Bustos Tovar, pp. 579-599. Madrid: Editorial Complutense.

García PADRÓn, Dolores. 2012. La derivación no canónica en los gentilicios españoles. En Wotjak, Gerd, Dolores García Padrón y María del Carmen Fumero Pérez (eds.). Estudios sobre lengua, cultura y cognición. Frankfurt am Main: Peter Lang.

García Sánchez, Jairo Javier. 2009. Toponimia y “exonimia”. Su reflejo en los medios de comunicación y su tratamiento en los libros de estilo. Español actual 91: 101-119. $160-170$.

2005. Irradiación analógica en la formación de gentilicios. Vox Románica 64:

Kordic, Raïssa y Mario Ferreccio. 2014. Topónimos y gentilicios de Chile. Santiago de Chile: RIL Editores.

LeNZ, Rodolfo. 1925. La oración y sus partes. Madrid: RFE.

Morera, Marcial (coord.). 2015. El gentilicio en español: aspectos teóricos y prácticos. Madrid: Arco/Libros.

2015. El gentilicio en español: tipos, significaciones y sentidos. En Morera, Marcial (coord.). 2015. El gentilicio en español: aspectos teóricos y prácticos, pp. 11-96. Madrid: Arco/Libros.

2012b. El concepto de gentilicio. En Campos Souto, Mar, Ramón Mariño, José Ignacio Pérez Pascual y Antonio Rifón (eds.). "Assí como es de suso dicho”: Estudios de morfología y léxico en homenaje a Jesús Pena. San Millán de la Cogolla, La Rioja: CILENGUA.

2012c. Gentilicios y seudogentilicios: mostración vs. descripción. Revista de lexicografia XVIII: 103-140.

2011a. La norma morfológica de los gentilicios españoles: del topónimo al gentilicio y del gentilicio al topónimo. La norma lingüística del español. Varsovia: Instituto de Estudios Ibéricos e Iberoamericanos de la Universidad de Varsovia/Museo de Historia del Movimiento Popular Polaco.

2011b. El género gramatical en español desde el punto de vista semántico. Frankfurt am Main: Peter Lang.

Oroz, Rodolfo. 1934. Sobre los sufijos de los nombres gentilicios chilenos. Anales de la Facultad de Filosofia y Educación de la Universidad de Chile I/1: 51-54.

1966. La lengua castellana en Chile. Santiago: Universidad de Chile.

Pena, Jesús. 1999. Partes de la morfología. Las unidades del análisis morfológico. En Bosque, Ignacio y Violeta Demonte (dirs.). Gramática descriptiva de la lengua española. Madrid: Espasa.

RaIner, Franz. 1999. La derivación adjetival. En Bosque, Ignacio y Violeta Demonte (dirs.). Gramática descriptiva de la lengua española. Madrid: Espasa. 
Real Academia Española. 1917. Gramática de la lengua castellana. Madrid: Perlado, Páez y Compañía (Sucesores de Hernando). 2009. Nueva gramática de la lengua española. Madrid: Espasa.

Seco, Manuel. 1989. Gramática esencial del español. Madrid: Espasa-Calpe.

Valdivieso, Humberto y Jaime Soto-Barba. 2002. Condiciones y restricciones sociales y lingüísticas para la aparición y formación de los gentilicios. Nueva Revista del Pacífico 47: 43-51.

Varela, Soledad. 1990. Fundamentos de morfología. Madrid: Síntesis.

WierzBiCKA, ANNA. 1986. What's in a noun? (or: How do nouns differ in meaning from adjetives?). Studies in Language 10 (2): 353-389. 